\title{
Assigning a house for refugees: An application of a multiple criteria nominal classification method
}

\author{
Ana Sara Costa - Isabella M. Lami · Salvatore \\ Greco · José Rui Figueira · José Borbinha
}

\begin{abstract}
This paper proposes the use of a Multiple Criteria Decision Aiding (MCDA) nominal classification method to tackle a dramatic current social problem: the accommodation system for refugees. In recent years, the number of people in need of protection and assistance as a consequence of forced displacement has drastically increased. As many other European cities, Turin (Italy) offers to refugees temporary places for a limited time span, but they are insufficient and often inadequate. Meanwhile, there are several underused buildings that can potentially be used to cover the refugees' needs of housing and facility. Combining these two aspects, this study aims at contributing to the definition of an urban strategy and improve the decision aiding process related to the accommodation system in Turin. We adopt a recently developed MCDA method to tackle the problem of accommodation of migrants, that is, the CAT-SD (CATegorization by Similarity-Dissimilarity) method. We face a nominal classification problem where underused buildings located in the city of Turin are assigned to categories (i.e., three migrant status). A decision model is constructed based on the judgments of the experts. Thus, the application of
\end{abstract}

A. S. Costa

CEG-IST, Instituto Superior Técnico, Universidade de Lisboa, Lisboa, Portugal

INESC-ID, Instituto Superior Técnico, Universidade de Lisboa, Lisboa, Portugal

E-mail: anasaracosta@tecnico.ulisboa.pt

I. M. Lami

Interuniversity Department of Regional and Urban Studies and Planning, Politecnico di Torino, Torino, Italy

E-mail: isabella.lami@polito.it

S. Greco

Department of Economics and Business, University of Catania, Catania, Italy

Portsmouth Business School, Centre of Operations Research and Logistics (CORL), University of Portsmouth, Portsmouth, United Kingdom

E-mail: salgreco@unict.it

J. R. Figueira

CEG-IST, Instituto Superior Técnico, Universidade de Lisboa, Lisboa, Portugal

E-mail: figueira@tecnico.ulisboa.pt

J. Borbinha

INESC-ID, Instituto Superior Técnico, Universidade de Lisboa, Lisboa, Portugal

E-mail: jlb@tecnico.ulisboa.pt 
the method allows to identify an adequate category (or categories) of migrant status for each building.

Keywords Multiple Criteria Decision Aiding · Nominal classification · Migration · Urbanism · Planning

\section{Introduction}

At the end of 2017, 68.5 million people were in need of protection and assistance as a consequence of forced displacement. This phenomenon concerns the highest levels of forced displacement globally recorded since World War II, with a dramatic increase in the number of refugees, asylum seekers and internally displaced people across various regions of the world, as a result of conflict and persecution. In 2017, 25.4 million were refugees and 3.1 million were asylum seekers. According to the United Nation High Commissioner for Refugees (UNHCR), $52 \%$ of the global refugee population are children under 18 - the highest proportion in a decade - including many who are unaccompanied or separated from their families [30]. In this context, and starting from the fact that most refugees nowadays live in urban areas $(58 \%)$, the paper proposes a possible answer to one of the first very concrete demands arisen by the universal and dramatic phenomenon of the migration: the need of a house.

On the one hand, some European cities are emptying and, on the other hand, a large number of people are looking for a home. It is important to give the right scale to this intersection, and to use an approach that would allow to consider not just a single building, but the problem as a whole. The paper illustrates the application of an innovative Multiple Criteria Decision Aiding (MCDA) [18] nominal classification method, based on the concepts of similarity and dissimilarity, CAT-SD (CATegorization by Similarity-Dissimilarity) [13], to tackle the problem of the refugees accommodation. Using an Italian case study, in the city of Turin, the paper shows how to assign a set of underused buildings to three nominal categories representing the migrant status (asylum seeker, refugee, and family member by reunification). Turin, as the majority of European cities, offers temporary places to refugees for a limited time span, spaces that are insufficient and often inadequate. The lack of dedicated areas for hosting people in the waiting period for the residence permit creates the need of services appropriated for each particular case. At the same time, it is crucial to develop a network connecting the several welfare states already existing in the territory. In the meanwhile, there are several underused buildings that can potentially be used to cover the needs of housing and facility of this type of migrants.

Conscious that the phenomenon of forced displacement represents a serious political problem with implications that will not be explored here, our aim is to discuss the possible contribution of the use of the CAT-SD method for defining an urban strategy regarding the accommodation system. In opposition to ordinal classification problems (or sorting), nominal classification problems are characterized by considering predefined categories not preferentially ordered [15,32]. The CAT-SD method was designed with the purpose of offering aid to the Decision Maker (DM) to classify objects of the decision (actions or alternatives, in our case, buildings) into groups predefined in a nominal way (i.e., not rank ordered). In this case, a set of underused buildings judged as potential places for hosting migrants in the city of Turin have to be assigned to categories - migrant status. Thus, buildings assigned to a given category will be used to host a certain profile of migrants. A co-constructed process through interaction between the analysts and the experts was followed. The first application of the CAT-SD to a real-world case, which involves the adaptive reuse of buildings for cultural uses, can be found in [14]. The innovation of the current paper is in the use of CAT-SD as a decision support for a serious social problem (for an extensive discussion on the application of MCDA decision support approach to social problems, 
see [1]). In comparison to other existing methods (e.g., $[7,8,20,23])$ to deal with MCDA nominal classification problems, CAT-SD presents advantage to our study for the following main reasons: (i) it allows to model similarity and dissimilarity judgments in pairwise comparison of actions; (ii) it is possible to take into account interactions between criteria; and (iii) distinct parameters may be defined per category.

The paper is organized as follows. Section 2 briefly introduces CAT-SD method. Section 3 presents the case study, providing data and describing the construction of the decision model, with details about the interaction with the experts during the decision aiding process. Section 4 provides the obtained results and a discussion about them. Section 5 presents some social implications of the study. Section 6 concludes the paper and proposes further research directions.

\section{Cat-SD: An overview}

The CAT-SD method was designed with the purpose of dealing with decision aiding contexts in which the classification problem involves a set of actions $\left(A=\left\{a_{1}, \ldots, a_{i} \ldots\right\}\right)$, assessed on a set of criteria $\left(G=\left\{g_{1}, \ldots, g_{j}, \ldots, g_{n}\right\}\right)$, to be assigned to a set of categories previously defined in a nominal way $\left(C=\left\{C_{1}, \ldots, C_{h}, \ldots, C_{q}, C_{q+1}\right\}\right.$, where $C_{q+1}$ is a dummy category to receive actions that cannot eventually be assigned to the other categories) [13]. This method can handle heterogeneous criteria and interaction between pairs of criteria. Actions are assigned to categories based on similarity and dissimilarity measures, which are assessed by pairwise comparisons of actions, while all criteria are considered. The method is mainly focused on likeness between actions (objects) and reference actions (referents). Thus, the categorization provided by this method is based on the comparison of likeness degrees (computed by pairwise comparison of actions on several criteria) to likeness thresholds (defined per category).

The following assumptions must be taken into account:

1. The categories to which the actions are assigned are not ordered (nominal categories);

2. Each category is defined by a set of reference actions;

3. Each category is previously defined to receive similar actions that might be processed in an identical way.

In the CAT-SD method, a set of preference parameters are needed. The main parameters are listed above:

1. Reference actions.

A set of reference actions is defined per category. It contains one or more representative actions of the category. Reference actions can be viewed as examples of actions that should belong to the category. Let $B_{h}=\left\{b_{h 1}, \ldots, b_{h \ell}, \ldots, b_{h\left|B_{h}\right|}\right\}$ denote the set of reference actions of category $C_{h}$, for $h=1, \ldots, q$, and $B=\left\{B_{1}, \ldots, B_{h}, \ldots, B_{q+1}\right\}$ the set of all sets of reference actions, with $B_{q+1}=\emptyset$.

2. Per-criterion similarity-dissimilarity functions.

For modeling purposes, a per-criterion similarity-dissimilarity function (SD function) is defined for each criterion (for more details, see [13]). It allows to obtain a measure of similarity and dissimilarity between two actions. In particular, it is used to compare the performance of an action, $g_{j}(a)$, to the performance of a reference action, $g_{j}(b)$, on a given criterion. In what follows, we present a general way of defining a SD function for a given criterion $g_{j}$ (assume that the criterion is to be maximized, without loss of generality). Consider an action $a$ that has to be assigned to the nominal categories and an action $b$ representing a reference action (a referent). Let $E_{j}$ denote the scale of criterion $g_{j}$ bounded from below by $g_{j}^{\text {min }}$ and from above by $g_{j}^{\max }$. Consider the difference of performances of $a$ and $b, \Delta_{j}(a, b)=\operatorname{diff}\left\{g_{j}(a), g_{j}(b)\right\}$ 
(when using ratio and interval scales, dif $f\left\{g_{j}(a), g_{j}(b)\right\}=g_{j}(a)-g_{j}(b)$, and when using ordinal scales, diff $\left\{g_{j}(a), g_{j}(b)\right\}$ corresponds to the number of performance levels in between $g_{j}(a)$ and $\left.g_{j}(b)\right)$.

A per-criterion similarity-dissimilarity function is a real-valued function, $f_{j}\left(\Delta_{j}(a, b)\right)$, that has as output a value within the range $[-1,1]$. It has to present the following features:

(a) $f_{j}$ is a non-decreasing function, in the interval $\left[-\operatorname{diff}\left\{g_{j}^{\max }, g_{j}^{\min }\right\}, 0\right]$;

(b) $f_{j}$ is a non-increasing function, in the interval $\left[0, \operatorname{diff}\left\{g_{j}^{\max }, g_{j}^{\min }\right\}\right]$;

(c) $f_{j}>0$ iff criterion $g_{j}$ contributes to similarity;

(d) $f_{j}<0$ iff criterion $g_{j}$ contributes to dissimilarity.

This function is also used to define:

- A per-criterion similarity function: $s_{j}(a, b)= \begin{cases}f_{j}\left(\Delta_{j}(a, b)\right), & \text { if } f_{j}\left(\Delta_{j}(a, b)\right)>0 \\ 0, & \text { otherwise }\end{cases}$
- A per-criterion dissimilarity function: $d_{j}(a, b)= \begin{cases}f_{j}\left(\Delta_{j}(a, b)\right), & \text { if } f_{j}\left(\Delta_{j}(a, b)\right)<0 \\ 0, & \text { otherwise }\end{cases}$

3. Criteria weights.

A set of weights, representing the relative importance of criteria, is associated with the criteria per category. Let $k_{j}^{h}$ denote each non-normalized weight associated with criterion $g_{j}$, for $h=1, \ldots, q$ and $j=1, \ldots, n$. Let $k^{h}=\left(k_{1}^{h}, \ldots, k_{j}^{h}, \ldots, k_{n}^{h}\right)$ denote a set of weights, such that $k_{j}^{h}>0$, for $h=1, \ldots, q$.

4. Interaction coefficients.

The following three types of interaction effects between pairs of criteria can be considered (see, for example, $[9,13,16])$ :

(a) Mutual-strengthening effect: If two criteria, $g_{j}$ and $g_{\ell}$, are in favor of similarity, then their contribution to the comprehensive similarity between $a$ and $b$ must be larger than the sum $k_{j}^{h}+k_{\ell}^{h}$, for a category $C_{h}$, for $h=1, \ldots, q$. There is a synergy between the two criteria, and this effect can be modeled by a positive mutual-strengthening coefficient $k_{j \ell}^{h}$, for $h=1, \ldots, q\left(\right.$ with $\left.k_{j \ell}^{h}=k_{\ell j}^{h}\right)$;

(b) Mutual-weakening effect: If two criteria, $g_{j}$ and $g_{\ell}$, are in favor of similarity, then their contribution to the comprehensive similarity between $a$ and $b$ must be smaller than the sum $k_{j}^{h}+k_{\ell}^{h}$, for a category $C_{h}$, for $h=1, \ldots, q$. The effect of those two criteria favoring the similarity, when a degree of redundancy between those criteria exists, can be modeled by a negative mutual-weakening coefficient $k_{j \ell}^{h}$, for $h=1, \ldots, q$ (with $k_{j \ell}^{h}=k_{\ell j}^{h}$ );

(c) Antagonistic effect: If a criterion, $g_{j}$, is in favor of similarity and another criterion, $g_{p}$, is in favor of dissimilarity, then the contribution of the criterion $g_{j}$ to the similarity must be smaller than the weight $k_{j}^{h}$, for a category $C_{h}$, for $h=1, \ldots, q$. Criterion $g_{p}$ has an antagonistic effect over criterion $g_{j}$. This effect can be modeled by a negative antagonistic coefficient $k_{j p}^{h}$, for $h=1, \ldots, q$.

The CAT-SD method is based on two main concepts: similarity and dissimilarity. Both similarity and dissimilarity measures on multiple criteria are taken into account to compute an overall likeness degree between two actions. For the construction of a likeness relation between two actions, say $a$ and $b$, the following elements are needed:

1. Comprehensive similarity.

A way to measure the overall similarity between actions $a$ and $b$ is presented as follows, taking into account the contribution of all criteria to the similarity, the criteria weights and 
the interaction coefficients, as well as some dissimilarity values derived from antagonist effects:

$$
s^{h}(a, b)=\frac{1}{K^{h}(a, b)}\left(\sum_{j \in G} k_{j}^{h} s_{j}(a, b)+\sum_{\{j, \ell\} \in M^{h}} z\left(s_{j}(a, b), s_{\ell}(a, b)\right) k_{j \ell}^{h}+\sum_{(j, p) \in O^{h}} z\left(s_{j}(a, b),\left|d_{p}(a, b)\right|\right) k_{j p}^{h}\right),
$$

where

$$
K^{h}(a, b)=\sum_{j \in G} k_{j}^{h}+\sum_{\{j, \ell\} \in M^{h}} z\left(s_{j}(a, b), s_{\ell}(a, b)\right) k_{j \ell}^{h}+\sum_{(j, p) \in O^{h}} z\left(s_{j}(a, b),\left|d_{p}(a, b)\right|\right) k_{j p}^{h},
$$

and $z(x, y)=x y$, for $h=1, \ldots, q$.

The set $M^{h}$ contains all pairs of criteria, $g_{j}$ and $g_{\ell}$, such that $f_{j}\left(\Delta_{j}(a, b)\right)>0$ and $f_{\ell}\left(\Delta_{\ell}(a, b)\right)>$ 0 (for mutual-interaction effects), and the set $O^{h}$ contains all pairs of criteria, $g_{j}$ and $g_{p}$, such that $f_{j}\left(\Delta_{j}(a, b)\right)>0$ and $f_{p}\left(\Delta_{p}(a, b)\right)<0$ (for antagonistic effects between the ordered pair of criteria $\left.\left(g_{j}, g_{p}\right)\right)$. The following condition must be fulfilled (it guarantees that the contribution of a criterion to the comprehensive similarity is not negative):

$$
k_{j}^{h} \quad-\sum_{\left\{\{j, \ell\} \in M^{h}: k_{j \ell}^{h}<0\right\}}\left|k_{j \ell}^{h}\right|-\sum_{(j, p) \in O^{h}}\left|k_{j p}^{h}\right| \geqslant 0, \text { for all } j \in G ; h=1, \ldots, q .
$$

2. Comprehensive dissimilarity.

A way to measure the overall dissimilarity can be defined as follows, taking into account the contribution of all criteria to the dissimilarity between actions $a$ and $b$ :

$$
d(a, b)=\prod_{j=1}^{n}\left(1+d_{j}(a, b)\right)-1
$$

3. Comprehensive likeness.

A function is used to assess the degree to which action $a$ is alike to action $b$. For that, it is necessary to aggregate the comprehensive similarity and dissimilarity functions. A way of modeling the likeness degree between actions $a$ and $b$ is through the following comprehensive likeness function:

$$
\delta(a, b)=s^{h}(a, b)(1+d(a, b)) .
$$

An additional preference parameter is needed: a threshold must be defined for each category as the minimum likeness degree judged necessary to say that action $a$ is alike action $b$. Let $\lambda^{h}$ denote the likeness threshold of category $C_{h}$, for $h=1, \ldots, q$. It takes a value within the range $[0.5,1]$.

Based on the likeness degree between an action and a set of reference actions, and according to the likeness threshold chosen for a given category, a $\lambda$-likeness binary relation can be defined as follows:

$$
a S\left(\lambda^{h}\right) B_{h} \Leftrightarrow \delta\left(a, B_{h}\right) \geqslant \lambda^{h}
$$

where

$$
\delta\left(a, B_{h}\right)=\max _{\ell=1, \ldots,\left|B_{h}\right|}\left\{\delta\left(a, b_{h \ell}\right)\right\}
$$

For a likeness threshold previously defined, $\lambda^{h} \in[0.5,1]$, for $h=1, \ldots, q$, the assignment procedure of the CAT-SD method can be presented as follows:

i) Compare action $a$ with set $B_{h}$, for $h=1, \ldots, q$;

ii) Identify $U=\left\{u: a S\left(\lambda^{u}\right) B_{u}\right\}$; 
iii) Assign action $a$ to category $C_{u}$, for all $u \in U$;

$i v$ ) If $U=\emptyset$, assign action $a$ to category $C_{q+1}$.

According to the assignment procedure, the CAT-SD method provides one category or a set of possible categories to which an action $a$ can be assigned (it may be the dummy category, meaning that action $a$ is not suitable to the remaining categories).

\section{Case study: The decision aiding modeling process}

The present case study aims at studying the suitability of underused buildings located in Turin to forced displaced people with distinct migrant status. This section presents the modeling decision aiding process followed during the construction of the nominal classification model using the CATSD method, including the main actors involved in this study, their roles and interaction, the data related to the application of the method, and the preference information used for modeling the decision problem at hand.

\subsection{The decision process}

The proposed approach consists of constructing a decision model to represent the decision problem and the preferences of the DM. Figure 1 illustrates the diagram of the sequence of steps followed during the MCDA modeling process. Accordingly, the process comprises the following main steps:

1. Step 1: Problem definition.

This study has involved several stakeholders who have the role of actors of the decision, differently acting in the various steps of the MCDA decision aiding process. The authors have acted as analysts (or facilitators) aiming at building a decision model. After some discussions, it has been identified a nominal classification problem involving several points of view (see Subsection 3.2);

2. Step 2: Input data.

The main data needed includes a set of actions, a set of criteria, and a set of nominal categories. The assessment of each action according to each criterion allows to obtain a performance table (see Subsection 3.3);

3. Step 3: Preference information.

In order to construct a CAT-SD model, it is necessary to build in interaction with the DM the per-criterion similarity-dissimilarity functions, determine a set of criteria weights and interaction coefficients, define each category by a set of reference actions, and establish a value for the likeness threshold of each category (see Subsection 3.4, and, for more details, see Section 2);

4. Step 4: Results.

According to the constructed (validated) decision model, by applying the CAT-SD method, it is possible to obtain the classification of the actions into the nominal categories (computations). Validations of the nominal classification model and the results are necessary. The model can be revised and modifications can be made on the previous steps (i.e., the DM revises the input data and/or preference information). The analysts provide recommendations to the DM regarding the decision problem based on the final results (see Section 4). 


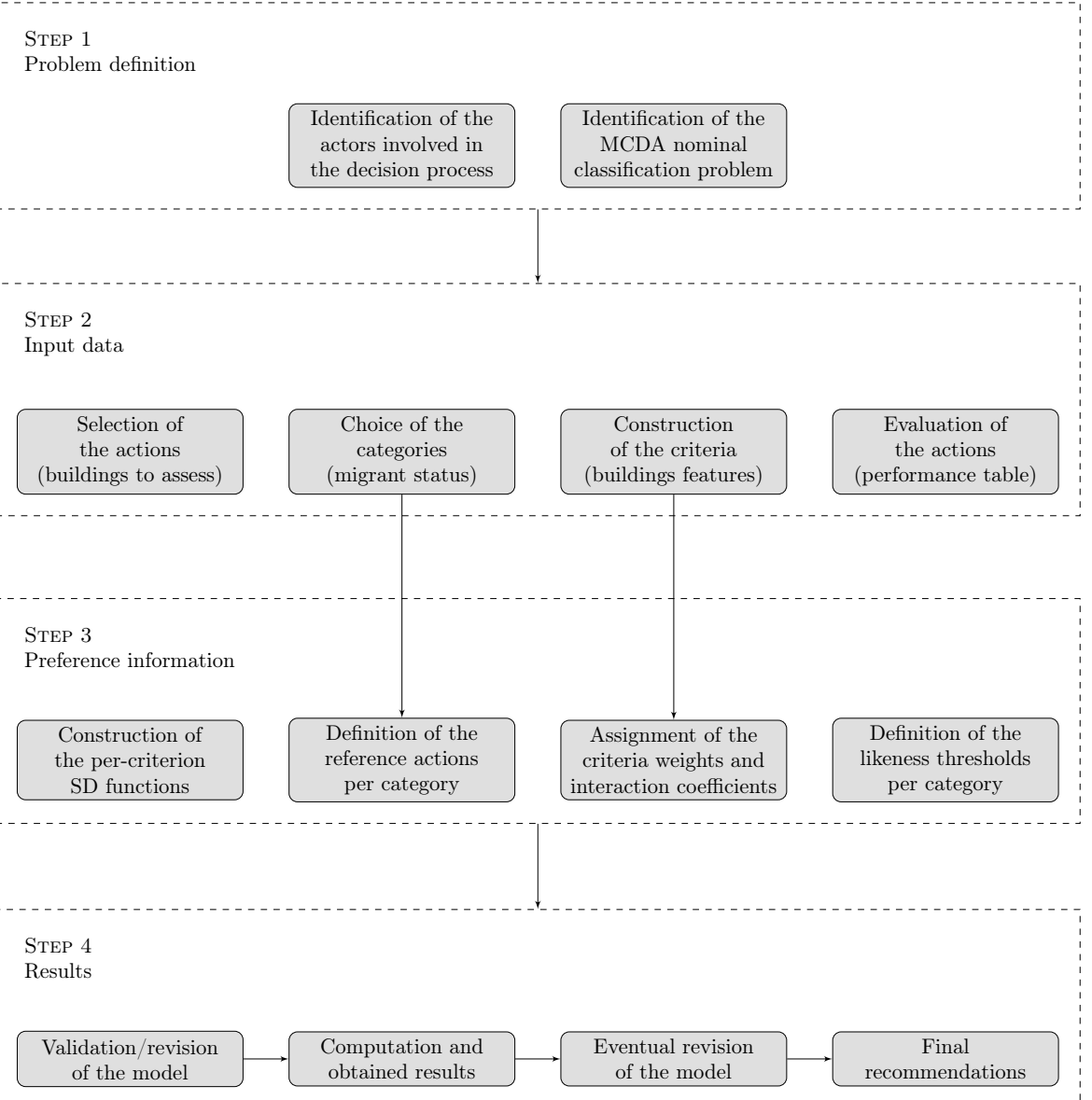

Fig. 1 Diagram of the decision aiding process to build the CAT-SD model.

\subsection{Problem definition}

In the present study, several stakeholders have been involved, and some of them have acted as DM (experts). The authors have acted as analysts by facilitating the decision aiding process. A co-constructive process was followed to build a decision model, meaning that the analysts and the DM have interacted. Through interviews, the executive of the prefecture of Turin, from the area "Civil Rights, Foreign Citizenship of the Stranger, Immigration and Asylum Rights" and the executive of "Immigration and Asylum" in the municipality of Turin have contributed to the definition of the criteria rights, and to the clarification of migrants' characteristics and needs, in order to define reference buildings and likeness thresholds. The responsible for Coordination of Planning (City Planning Direction of Turin) collaborated in the process of selecting the potential actions to be evaluated. Focus group meetings with experts in architecture, urban planning (with a specific expertise in accommodating migrants), and project evaluation took place to apply the cards method for determining the criteria weights (revised Simos procedure [17]). The responsible for the section of police who manage migrants also contributed to our understanding of the complex process of accommodation system for refugees, given in this way fundamental information to construct the criteria and defining the reference actions. 
In this case study, a set of potential underused buildings in the city of Turin were considered to be assigned into categories defined in a nominal way (i.e., there is no relation of importance or preference among categories). For this decision problem, we have applied the CAT-SD method, as depicted in Figure 2.

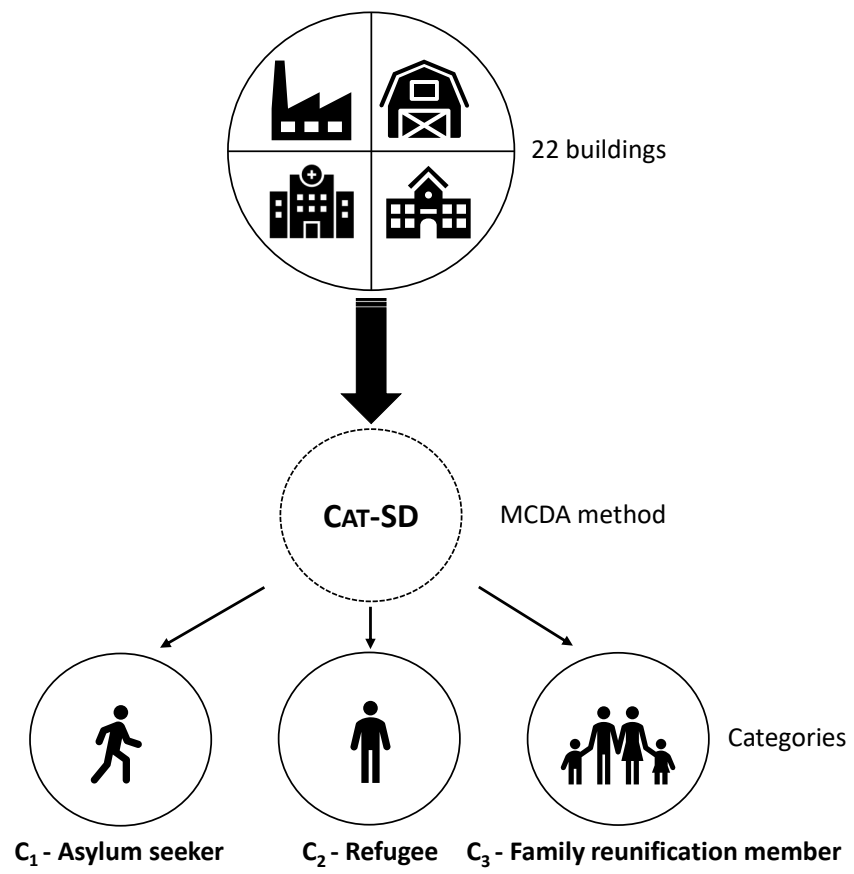

Fig. 2 Case study overview (adapted from [10]).

\subsection{Input data}

In this subsection, we present the data used in the case study (step 2 in Figure 1). The main data of the decision problem at hand is composed by the following three sets:

1. Underused buildings located in the city of Turin;

2. Building's characteristics, considering spatial and geographical points of view (these elements are used to construct the set of criteria);

3. Nominal categories representing distinct migrant status.

\subsubsection{Selection of the actions}

The current sample includes twenty-two buildings in Turin, which were selected as potential spaces to host migrants. The buildings selected for the case study were chosen with the city planning department manager of Turin, who stressed out that in the city there are already some reception centers for migrants and, at the same time, there are a lot of squatting phenomena often tolerated by the public administration, but the problem persists. He suggested twenty-two 
"waiting space", buildings of different size and previous uses, waiting for an opportunity to come back to the city life. Table 1 identifies this set of buildings. It should be mentioned that there is no need of totally knowing the set of buildings in the initial phase of the model construction. This means that the method could be used to assess other buildings not considered in the initial sample, without any need to change the constructed model.

Table 1 Set of underused buildings in Turin

\begin{tabular}{lllr}
\hline Code & Structural typology & \multicolumn{1}{c}{ Current use } & Available surface $\left(\mathrm{m}^{2}\right)$ \\
\hline$a_{1}$ & Industrial building & Underused & 5200 \\
$a_{2}$ & Industrial building & Underused & 43623 \\
$a_{3}$ & Hospital & Underused & 400 \\
$a_{4}$ & Industrial building & Partially occupied & 3865 \\
$a_{5}$ & Military building & Underused & 24783 \\
$a_{6}$ & Barrack & Project ongoing & 19978 \\
$a_{7}$ & Industrial building & Underused & 6360 \\
$a_{8}$ & Industrial building & Partially occupied & 7000 \\
$a_{9}$ & Brewery & Partially occupied & 5000 \\
$a_{10}$ & Hospital & Underused & 11367 \\
$a_{11}$ & Industrial building & Underused & 15192 \\
$a_{12}$ & Industrial building & Underused & 9000 \\
$a_{13}$ & Industrial building & Underused & 3900 \\
$a_{14}$ & Office & Underused & 2300 \\
$a_{15}$ & Industrial building & Underused & 31000 \\
$a_{16}$ & Industrial building & Partially occupied & 10200 \\
$a_{17}$ & Barrack & Partially occupied & 9126 \\
$a_{18}$ & Farmstead & Project ongoing & 1300 \\
$a_{19}$ & Hospital & Underused & 5700 \\
$a_{20}$ & Industrial building & Underused & 7000 \\
$a_{21}$ & Hospital & Underused & 1815 \\
$a_{22}$ & Industrial building & Project ongoing & 35000 \\
\hline & & &
\end{tabular}

Depending on the characteristics of the buildings, they can be more adequate for hosting a certain person or a group of people. Indeed, the suitability of a building may depend on a multitude of features from different nature and distinct points of view. In this study, the buildings were assessed according to their spatial characteristics, as well as their location with respect to some specific services in the city of Turin, which are judged important for people forced to displace from their Country, such as bureaucratic, psychology, and integration services, among others.

\subsubsection{Choice of the categories}

The following three distinct categories were predefined to receive buildings (see Figure 1, step 2):

$-C_{1}$ : Asylum seeker. "A person who has left her/his country of origin and formally applied for asylum in another country but whose application has not yet been concluded" [24];

$-C_{2}$ : Refugee. "A person who owing to a well-founded fear of being persecuted for reasons of race, religion, nationality, membership of a particular social group or political opinion, is outside the country of his nationality and is unable or, owing to such fear, is unwilling to avail himself of the protection of that country; or who, not having a nationality and being outside 
the country of his former habitual residence as a result of such events, is unable or, owing to such fear, is unwilling to return to it" [29]. A person is officially a refugee when she/he has her/his claim for asylum accepted by the government;

$-C_{3}$ : Family reunification member. Immediate family members directly connected to category $C_{2}$.

It should be remarked that an order does not exist among these three categories, even if they are coded with numbers. Indeed, the categories correspond to distinct migrant status with different rights and needs, which do not present a preference order among them. An additional category $C_{4}$ has been considered to eventually receive buildings assessed as not suitable to any migrant status according to the decision model.

\subsubsection{Construction of the set of the criteria and actions' evaluation}

In the CAT-SD method, multiple criteria can be considered, which must be defined as a coherent family of criteria [25-27]. In this study, the buildings were assessed according to twelve criteria considered relevant for the situation at hand from the experts' point of view $(n=12)$. The criteria have been defined with the contribution of an executive of the prefecture of Turin, area "Civil Rights, Foreign Citizenship of the Stranger, Immigration and Asylum Rights", and an executive of "Immigration and Asylum" in the municipality of Turin.

Three types of building typology (A, B, and C) were defined (Figure 3), based on existing examples of refugees' accommodation sites built in Germany. The choice of these cases is related to the fact that since 2015, when the German border was kept open, 300,000 refugees arrived and they continue to live in initial reception centers and collective accommodation, fact that could be interpreted as an indicator of the good quality of the accommodation sites ("not only to offer the new arrivals a roof over their heads in an emergency situation, but also to provide suitable and sustainable accommodation for them in the long term" [21]).

The criteria were constructed in heterogeneous scales, and an ordered preference scale of the possible performance levels was defined. This means that each criterion was associated with a preference direction: maximized (increasing) or minimized (decreasing). The following four scales were used:

- $E_{1}$ is a scale with two levels: no (0) and yes (1);

- $E_{2}$ is a scale with three levels: low - $L(1)$, medium - $M(2)$ and high - $H(3)$;

- $E_{3}$ is a scale with four levels: very low $-V L(1)$, low - $L(2)$, medium - $M(3)$ and high - $H$ (4);

- $E_{4}$ is a scale expressing distance between two places, in meter.

A list with the description of each criterion is presented as follows, where the first four criteria are of architectural nature and the remaining eight criteria are related to the location of the buildings to the network of services already existing in the Turin area [10]:

- $g_{1}$ : Typology A. This type of dwelling can accommodate a large number of people with spaces characterized by a low level of privacy. The building can host dormitories from five to ten people and common areas for services, such as washrooms, kitchen, recreation room, and classrooms. This typology can correspond to former industrial buildings, characterized by large open spaces easily divisible with removable structures (depending on the needs) and former barracks already structured in large dormitories and a series of common areas. It is plausible to think that the limited privacy of this typology can be acceptable for a first admission of people and for a short period of time, a situation that corresponds to the condition of an asylum seeker. In fact, an asylum seeker needs a temporary place to stay, 

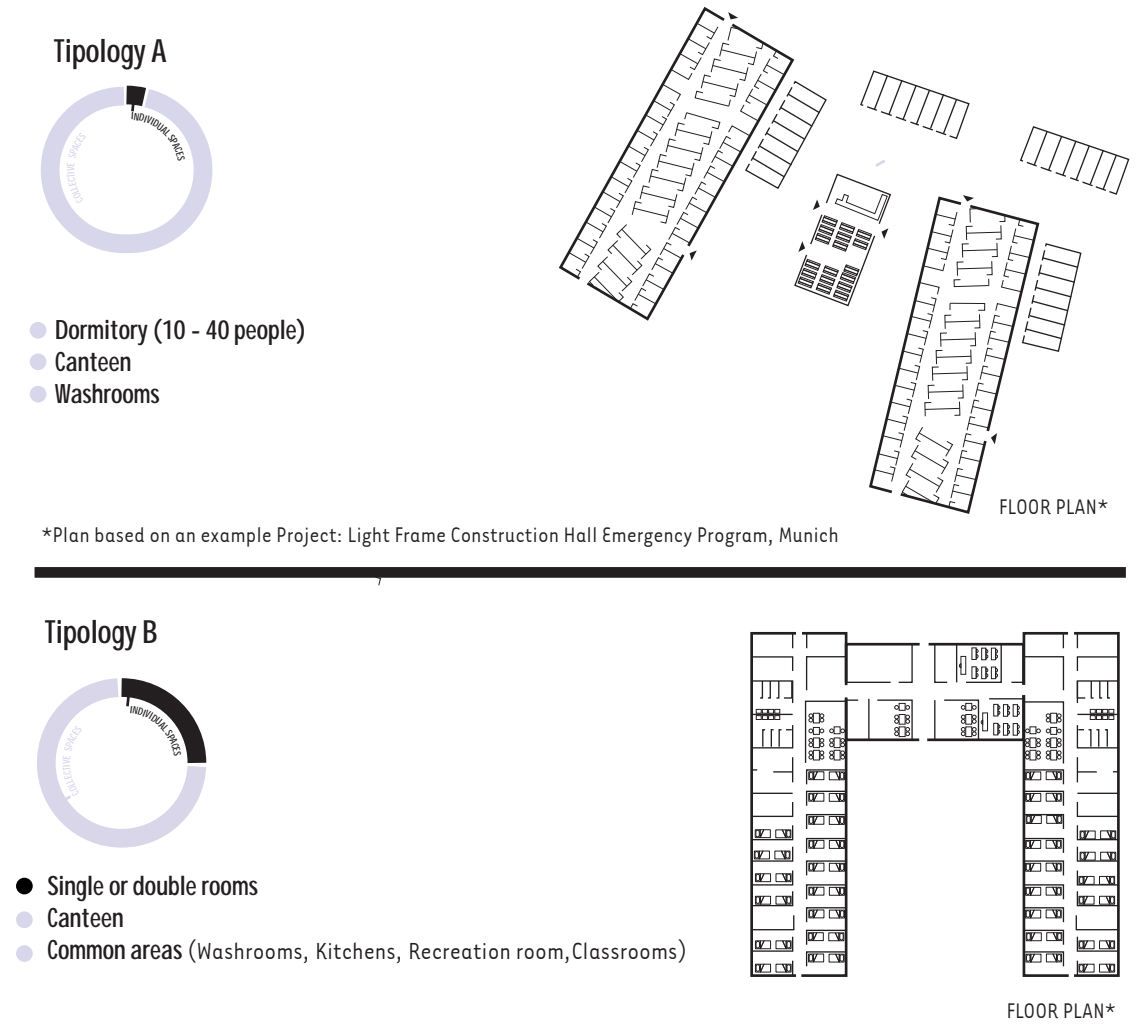

*Plan based on an example Project: Refugee accommodation, Munich

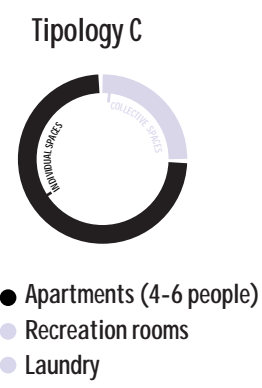

Plan based on an example Project: Permanent housing for refugees, Wedel
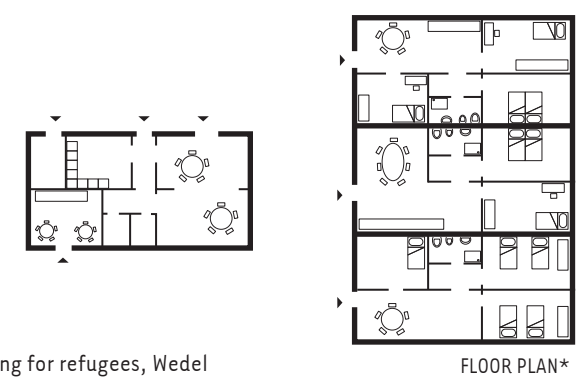

Fig. 3 Typologies A, B and C (adapted from [10]).

before the determination of her/his rights and status. It was used a qualitative scale, $E_{1}$, with two levels representing the presence and the absence of typology A in the building, considering that, in general, the presence is better than the absence of this type of typology (maximizing). Figure 3 shows a representation of an example of this type of typology; 
$-g_{2}$ : Typology B. This type of dwelling can host large number of people with varying degrees of private spaces. Single or double rooms are provided in the sleeping area, as well as common areas for services, such as washrooms, kitchen, recreation room, and classrooms. This typology can correspond to ex-hospitals and ex-military barracks, structured in medium to large dormitories and a series of common areas, with solid partition walls between the rooms and not simple removable walls that help provide more visual privacy than just an acoustic one (and, therefore, not complete). The higher level of privacy, compared to typology A, makes these types of buildings better suitable to accommodate people for a longer period of time, such as refugees, migrants with the recognized refugee status, who are in the phase of settlement and integration, or migrants who are in the attendance for the accession of the other family members by reunification, or even asylum seekers who exceed the six month of initial waiting period and needs more individual spaces, or also asylum seekers who arrives with family, requiring more private spaces. Scale $E_{1}$ was used as in $g_{2}$. For an example of typology B, see Figure 3;

- $g_{3}$ : Typology C. This type of dwelling can host small number of people with a high degree of privacy. It offers private apartments for living and sleeping zones; meanwhile it can offer some common areas, such as recreation rooms and laundry services, according to needs. The housing units can vary; their dimension is partly defined by the architectural and structural constraints set by the building to be restored. The offer of accommodation of different sizes allows to accommodate more or less numerous families. The typology $\mathrm{C}$ seems appropriate for a long phase of accommodation and, in this sense, it is suitable for refugee families with the recognized refugee status and members united with family reunification or families in the attendance of the family reunification status. The scale associated to this criterion was also $E_{1}$, and an example of typology $\mathrm{C}$ is illustrated in Figure 3;

- $g_{4}$ : Level of degradation. It represents the degradation state of the building, which can vary considerably depending on the structure and age of the building, the number of years of neglect, the maintenance conditions when in use, and the original intended use. The level of degradation affects substantially both the costs of recovery of the building and the time necessary for the restoration work, therefore it affects the effective possibility of using the property quickly. Three qualitative levels (low, medium, and high) were used to measure the degradation state of the building, using scale $E_{2}$. It was considered that the lower the level of degradation, the better (minimizing);

- $g_{5}$ : Public transportation. Public transportation represents the existing network of transportation system. The possibility to easily use public transport for people who cannot afford a car is an element that facilitates the integration into the city's work and school systems. In this sense, it seems particularly important for refugees and family members with recognized status. A scale with four qualitative levels (scale $E_{3}$ ) was associated to this criterion to measure the presence of public transportation near a building, considering that the higher, the better (maximizing);

- $g_{6}$ : Distance from prefecture. Prefecture is used by migrants for the obtainment of some documentation, such as ID card, fiscal code, demand for primary care, and citizenship for refugees. It is mainly attended by refugees with recognized status for their paperwork. The criterion scale $E_{4}$ was used to measure the distance from a certain building to the prefecture, in meters, considering that, in general, the closer they are, the better (minimizing);

- $g_{7}$ : Distance from police headquarters. Police headquarters provides identification of the asylum seeker through photo-signaling and the collection of fingerprints. It collects the application for international protection and acts as a gateway for all communications between the Territorial Commission (composed of prefecture, police, local authority, and representative of the UNHCR) and asylum seekers. It is a crucial point specially for asylum seekers, a place 
where they have to go several times to complete the documentation, and its proximity to temporary accommodation can be an element of simplification for the life of people just arrived in the Country. This criterion uses the same scale $\left(E_{4}\right)$ and preference direction (minimizing) as criterion $g_{6}$;

- $g_{8}$ : Distance from a bureaucratic assistance office. Some associations present in the city, in addition to the police headquarters, help migrants to draw up documents (e.g., enrollment in the national health system), to know and request the available services (such as the request for subsidies, housing contributions, access to rankings for social housing, etc.) Scale $E_{4}$ was associated to this criterion (minimizing);

- $g_{9}$ : Distance from psychology service. According to the World Health Organisation, the psychological and social stresses often experienced by refugees during migration can double the prevalence of severe disorders (psychosis, severe depression, and disabling anxiety), and increase the figures of mild to moderate mental disorders (e.g., mild and moderate forms of depression and anxiety disorders) from 10\% to 15-20\%. Several associations offer psychological assistance to help migrants recover from the traumas they have experienced in their home countries and those they face as they begin new lives. Scale $E_{4}$ was associated to this criterion (minimizing);

$-g_{10}$ : Distance from education services. Education services are designed specifically to enhance migrants learning skills and their civil integration in the new society. This service is provided by associations, which offer language courses, civil education, and several types of workshops. This service is important at each level of the inclusion process, to enhance the community engagement. As emphasized by UNHCR, "education protects refugee children and youth from forced recruitment into armed groups, child labor, sexual exploitation and child marriage. Education also strengthens community resilience. Education empowers by giving refugees the knowledge and skills to live productive, fulfilling and independent lives. Education enlightens refugees, enabling them to learn about themselves and the world around them, while striving to rebuild their lives and communities" [31]. Scale $E_{4}$ was associated to this criterion (minimizing);

$-g_{11}$ : Distance from integration services: Integration services are designed specifically to assist migrants with their inclusion and socialization needs. The service is provided by associations, which offer workshops, laboratories, cultural activities, and recreation events. This service has a greater importance at the second phase of the inclusion when the refugees and family members with recognized status could exploit better the services. Scale $E_{4}$ was associated to this criterion (minimizing);

- $g_{12}$ : Distance from placement service. Job placement services are designed specifically to support migrant's job seeking and to integrate them in the society. Service is provided by associations which offer internships, assistance with training and orientation programs. This is a service of particular importance for those who have the recognized refugee status who has official right to work. Scale $E_{4}$ was associated to this criterion (minimizing).

Table 2 summarizes the information related to the twelve criteria, providing a short description, the criteria scales and their preference direction (maximize or minimize).

Table 3 displays the performance of the buildings on each criterion.

\subsection{Preference information}

For the construction of a CAT-SD model it is necessary to obtain preference information from the DM, aiming to assign values to the preference parameters. This subsection is devoted to the 
Table 2 Set of criteria

\begin{tabular}{lllll}
\hline Code & \multicolumn{1}{c}{ Criterion } & \multicolumn{1}{c}{ Description } & Scale & Direction \\
\hline$g_{1}$ & Typology A & Presence of "Typology A" & $E_{1}$ & $\uparrow$ \\
$g_{2}$ & Typology B & Presence of "Typology B" & $E_{1}$ & $\uparrow$ \\
$g_{3}$ & Typology C & Presence of "Typology C" & $E_{1}$ & $\uparrow$ \\
$g_{4}$ & Level of degradation & Degradation state of building elements & $E_{2}$ & $\downarrow$ \\
$g_{5}$ & Public transportation & Degree of connection to public transports near the building & $E_{3}$ & $\uparrow$ \\
$g_{6}$ & Distance from prefecture & Distance from the prefecture of Turin & $E_{4}$ & $\downarrow$ \\
$g_{7}$ & Distance from police headquarters & Distance from the police headquarters of Turin & $E_{4}$ & $\downarrow$ \\
$g_{8}$ & Distance from a bureaucratic assistance office & Minimal distance from a place with bureaucratic services & $E_{4}$ & $\downarrow$ \\
$g_{9}$ & Distance from psychology service & Minimal distance from a place with psychology services & $E_{4}$ & $\downarrow$ \\
$g_{10}$ & Distance from education service & Minimal distance from a place with education services & $E_{4}$ & $\downarrow$ \\
$g_{11}$ & Distance from integration service & Minimal distance from a place with integration services & $E_{4}$ & $\downarrow$ \\
$g_{12}$ & Distance from job placement service & Minimal distance from a place with job placement services & $E_{4}$ & $\downarrow$ \\
\hline
\end{tabular}

Table 3 Buildings performances

\begin{tabular}{lrrrrrrrrrrrr}
\hline Building & $g_{1}$ & $g_{2}$ & $g_{3}$ & $g_{4}$ & $g_{5}$ & $g_{6}$ & \multicolumn{1}{c}{$g_{7}$} & $g_{8}$ & $g_{9}$ & \multicolumn{1}{c}{$g_{10}$} & \multicolumn{1}{c}{$g_{11}$} & $g_{12}$ \\
\hline$a_{1}$ & 1 & 0 & 1 & 3 & 4 & 2000 & 900 & 2500 & 1000 & 1000 & 1000 & 1000 \\
$a_{2}$ & 1 & 1 & 0 & 2 & 4 & 3200 & 2000 & 2700 & 3500 & 500 & 3200 & 1100 \\
$a_{3}$ & 0 & 1 & 1 & 1 & 3 & 4000 & 5000 & 3500 & 2000 & 4000 & 3400 & 5000 \\
$a_{4}$ & 1 & 0 & 1 & 3 & 3 & 1300 & 850 & 2200 & 1000 & 1000 & 1000 & 1000 \\
$a_{5}$ & 1 & 1 & 0 & 2 & 3 & 3400 & 2000 & 2900 & 4000 & 800 & 3100 & 900 \\
$a_{6}$ & 0 & 1 & 1 & 1 & 3 & 3300 & 5000 & 4100 & 4000 & 3100 & 3100 & 4500 \\
$a_{7}$ & 1 & 0 & 1 & 2 & 3 & 5000 & 7000 & 4100 & 500 & 3400 & 3300 & 5000 \\
$a_{8}$ & 0 & 0 & 1 & 1 & 3 & 5000 & 6000 & 3100 & 3000 & 3100 & 3200 & 3100 \\
$a_{9}$ & 1 & 1 & 0 & 1 & 3 & 5000 & 6000 & 3050 & 3000 & 3100 & 3200 & 3100 \\
$a_{10}$ & 1 & 1 & 0 & 2 & 3 & 2800 & 2000 & 1000 & 2500 & 800 & 100 & 800 \\
$a_{11}$ & 1 & 0 & 1 & 3 & 3 & 2800 & 2000 & 1000 & 2500 & 800 & 100 & 800 \\
$a_{12}$ & 1 & 1 & 1 & 3 & 3 & 2000 & 10 & 2500 & 2500 & 900 & 1000 & 900 \\
$a_{13}$ & 1 & 1 & 0 & 3 & 3 & 3100 & 1100 & 2700 & 3000 & 1000 & 2900 & 100 \\
$a_{14}$ & 0 & 0 & 1 & 2 & 2 & 3100 & 3300 & 3500 & 3200 & 3100 & 3200 & 2000 \\
$a_{15}$ & 1 & 0 & 1 & 3 & 2 & 6000 & 7000 & 3200 & 2500 & 2000 & 2500 & 3100 \\
$a_{16}$ & 1 & 1 & 0 & 2 & 2 & 2900 & 3000 & 3200 & 3200 & 3100 & 3100 & 2900 \\
$a_{17}$ & 1 & 1 & 0 & 2 & 2 & 6000 & 7000 & 5000 & 2000 & 6000 & 5000 & 6000 \\
$a_{18}$ & 0 & 0 & 1 & 2 & 2 & 5000 & 3500 & 1000 & 4000 & 1200 & 1100 & 1500 \\
$a_{19}$ & 0 & 1 & 0 & 1 & 2 & 1000 & 2000 & 2500 & 1000 & 1000 & 1000 & 1000 \\
$a_{20}$ & 0 & 1 & 1 & 1 & 1 & 3200 & 2800 & 2500 & 1000 & 1000 & 2700 & 1100 \\
$a_{21}$ & 0 & 1 & 0 & 3 & 1 & 6000 & 7000 & 5200 & 1100 & 3200 & 3700 & 6000 \\
$a_{22}$ & 1 & 0 & 1 & 2 & 1 & 4000 & 5000 & 4000 & 2700 & 2800 & 2000 & 5000 \\
\hline & & & & & & & & & & & &
\end{tabular}

process of eliciting such parameters with modeling purposes, corresponding to step 3 in Figure 1.

\subsubsection{Definition of the reference actions per category}

Modeling the set of categories basically comprises defining the sets of reference buildings. As previously mentioned (see Subsection 3.3 and step 3 of Figure 1), three categories were defined a priori representing three migrant status (or profile): asylum seeker $\left(C_{1}\right)$, refugee $\left(C_{2}\right)$, and family reunification member $\left(C_{3}\right)$. An additional category was considered with the purpose of receiving buildings that are eventually not adequate for any of the three considered categories (migrant status). Thus, we worked with four nominal categories. Note that no order exists among the categories (e.g., none of them is more important than another one).

At the legal level, these status are three conditions that underlie different rights and constraints, which have a different time duration and which express different spatial and welfare needs. These differences are not negligible in the decision problem and in the structuring of the reception system. 
Each category, representing a migrant status, was defined through a single representative building or a set of them, taken into account the purpose (i.e., host a certain profile of migrants). A reference building ("characteristic reference profile") is an example of a building judged representative of an adequate one for the corresponding migrant status. Thus, a reference building presents particular characteristics, i.e., representative performance values on each criterion. A reference building can be a real one or a dummy one (presenting certain characteristics considered representative). For category "reunification family member", the experts considered a single reference building as enough for defining the respective category. However, for categories "asylum seeker" and "refugee", one reference was not sufficient, but two reference buildings were defined by the experts. The performances of all reference buildings considered in this study are displayed in Table 4.

Table 4 Performance of the reference actions on all criteria

\begin{tabular}{|c|c|c|c|c|c|c|c|c|c|c|c|c|c|}
\hline Category & Reference action & $g_{1}$ & $g_{2}$ & $g_{3}$ & $g_{4}$ & $g_{5}$ & $g_{6}$ & $g_{7}$ & $g_{8}$ & $g_{9}$ & $g_{10}$ & $g_{11}$ & $g_{12}$ \\
\hline \multirow{2}{*}{ Asylum seeker } & $b_{11}$ & 1 & 1 & 0 & 1 & 3 & 1000 & 900 & 900 & 900 & 900 & 1500 & 1000 \\
\hline & $b_{12}$ & 1 & 1 & 0 & 2 & 2 & 1500 & 1100 & 1100 & 1000 & 1100 & 2000 & 2000 \\
\hline Refugee & $b_{21}$ & 0 & 1 & 1 & 1 & 4 & 3000 & 3000 & 4000 & 3000 & 500 & 1000 & 900 \\
\hline \multirow{2}{*}{ Family reunification member } & $b_{31}$ & 0 & 0 & 1 & 1 & 4 & 4000 & 4000 & 5000 & 4000 & 1000 & 1500 & 1000 \\
\hline & $b_{32}$ & 0 & 0 & 1 & 1 & 4 & 3000 & 3000 & 3000 & 1500 & 1000 & 2000 & 2000 \\
\hline
\end{tabular}

\subsubsection{Construction of the per-criterion SD functions}

As for preference parameters needed to construct a model according to the CAT-SD method, the following were considered (see also Section 2 and step 3 of Figure 1):

- Per-criterion similarity-dissimilarity functions: a way for modeling similarity and dissimilarity between a given building and a reference one, according to a single criterion. One function per criterion was defined;

- Criteria weights: relative importance of criteria considering each one of the three categories of migrant status individually;

- Interaction effects between criteria: interactions in some pairs of criteria for each category;

- Likeness thresholds: values needed to validate that a given building is judged sufficient similar to the set of reference buildings of a category (one likeness threshold per category).

For the first aspect, according to the preferences of the experts, SD functions for each one of the twelve criteria were constructed. Four different functions were defined, meaning that the SD function is the same for groups of criteria, as follows:

$$
\left.\left.\left.\left.\begin{array}{l}
g_{1} \\
g_{2} \\
g_{3}
\end{array}\right\} f_{1}\left(\Delta_{1}(a, b)\right) ; \quad g_{4}\right\} f_{4}\left(\Delta_{4}(a, b)\right) ; \quad g_{5}\right\} f_{5}\left(\Delta_{5}(a, b)\right) ; \quad g_{6}-g_{12}\right\} f_{6}\left(\Delta_{6}(a, b)\right) \text {. }
$$

It should be remarked that the construction of the functions is subjective, since it depends on the preferences and judgments of the DM. In what follows, we present some details about the judgments of the experts on the construction of the SD functions:

- $f_{1}\left(\Delta_{1}(a, b)\right)$ : For criteria related to the presence of a certain dwelling (typology A, B, or C), the $\mathrm{SD}$ function, $f_{1}$, was defined as follows: 
i) If a building, $a_{i}$ (in general, simply say $a$ ) and a reference building, $b_{h \ell}$ (simply say $b$ ), presents the "Typology" or if none of them do not presents the "Typology", then they are considered totally similar, thus $f_{1}\left(\Delta_{1}(a, b)\right)=1$;

ii) Otherwise, a neutral situation was considered, since the difference in terms of dwelling among buildings is relative and not that concrete to consider that they are dissimilar, thus $f_{1}\left(\Delta_{1}(a, b)\right)=0$.

Figure 4 depicts this SD function;

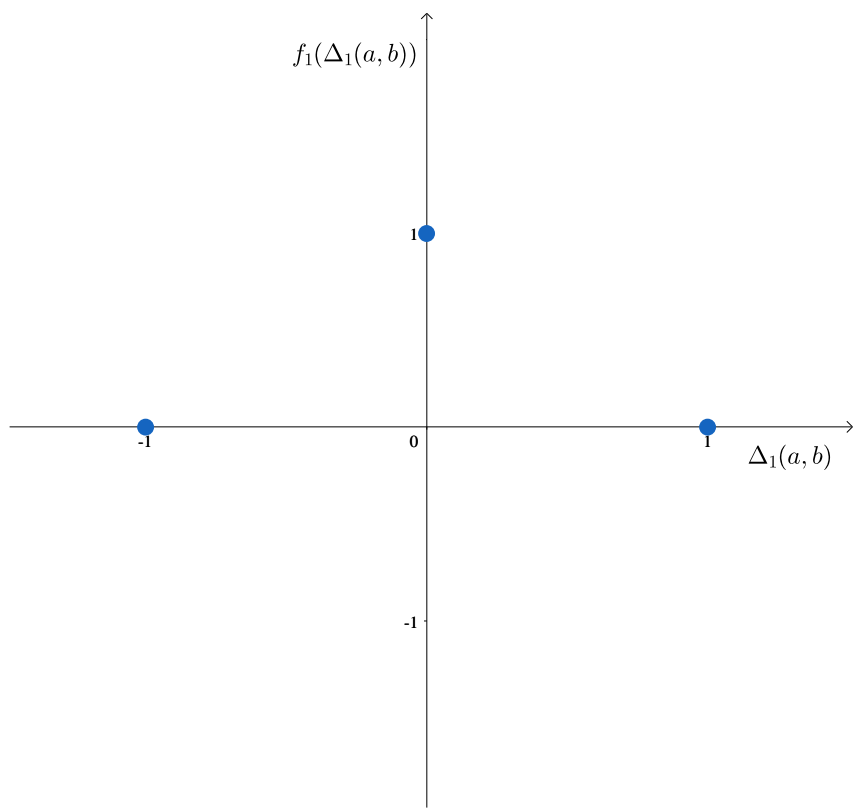

Fig. 4 Representation of the SD function $f_{1}$

- $f_{4}\left(\Delta_{4}(a, b)\right)$ : For criterion $g_{4}$ (level of degradation), according to the experts opinion, the following has been considered (see Figure 5):

$i$ ) If there is no difference between the level of degradation of $a$ and $b$, then they are totally similar on this aspect, therefore $f_{4}\left(\Delta_{4}(a, b)\right)=1$;

ii) If the absolute difference is one level (i.e., $L$ and $M$, or $M$ and $H$ ), there is some similarity, such that $f_{4}\left(\Delta_{4}(a, b)\right)=0.5$;

iii) If the absolute difference is two levels (i.e., $L$ and $H$ ), there is dissimilarity between the two buildings, such that $f_{4}\left(\Delta_{4}(a, b)\right)=-0.5$.

- $f_{5}\left(\Delta_{5}(a, b)\right)$ : For criterion $g_{5}$ (public transportation), the experts considered the following:

i) If there is no difference between performances of $a$ and $b$ (i.e., the building and the reference building have the same level of presence of public transportation), there is total similarity $\left(f_{5}\left(\Delta_{5}^{1}(a, b)\right)=1\right.$, with $\Delta_{5}^{1}(a, b)=\operatorname{diff}\{V L, V L\}=\operatorname{diff}\{L, L\}=\operatorname{diff}\{M, M\}=$ $\operatorname{diff}\{H, H\})$,

ii) If $a$ and $b$ have the level "very low" $(V L)$ and "low" $(L)$, respectively and vice-versa, there is a similarity with a value of $0.8\left(f_{5}\left(\Delta_{5}^{2}(a, b)\right)=0.8\right.$, assuming that $\Delta_{5}^{2}(a, b)=$ $\operatorname{diff}\{V L, L\}=\operatorname{diff}\{L, V L\})$;

iii) If they have "medium" $(M)$ and "high" $(H)$, the similarity has a value of $0.3\left(f_{5}\left(\Delta_{5}^{3}(a, b)\right)=\right.$ 0.3 , assuming that $\left.\Delta_{5}^{3}(a, b)=\operatorname{diff}\{M, H\}=\operatorname{diff}\{H, M\}\right)$; 


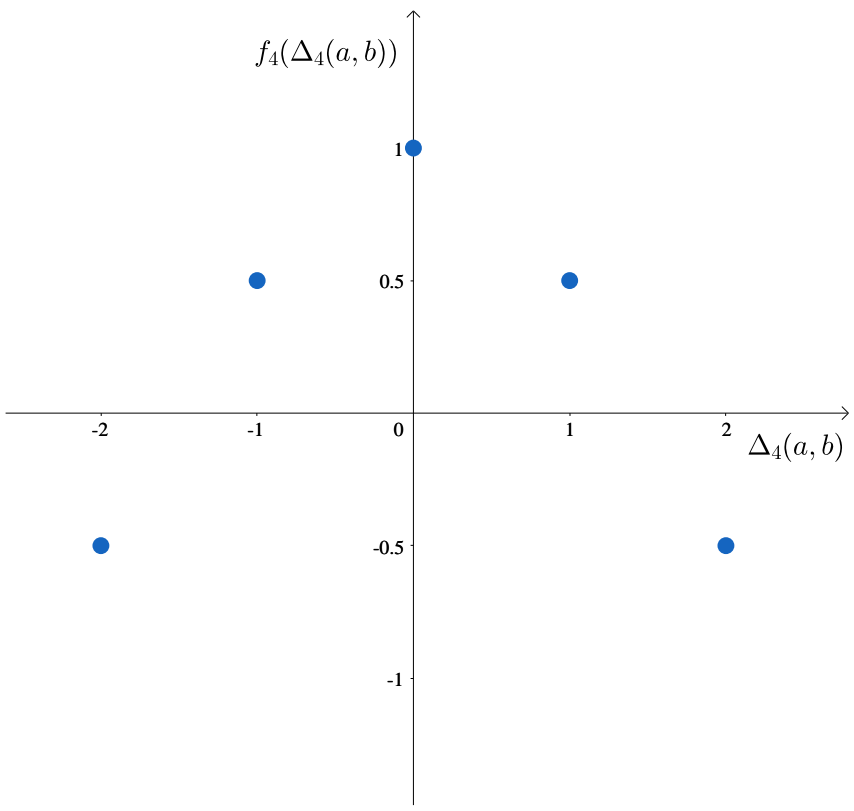

Fig. 5 Representation of the SD function $f_{4}$

$i v$ ) For the remaining differences of performances in pairs of levels $\left(\Delta_{5}^{4}(a, b)\right)$, it is neutral, therefore $f_{5}\left(\Delta_{5}^{4}(a, b)\right)=0$;

$v$ ) If they have extreme levels, that is, "very low" $(V L)$ and "high" $(H)$, there is total dissimilarity, that is, $f_{5}\left(\Delta_{5}^{5}(a, b)\right)=-1$, with $\Delta_{5}^{3}(a, b)=\operatorname{diff}\{V L, H\}=\operatorname{diff}\{H, V L\}$.

- $f_{6}\left(\Delta_{6}(a, b)\right)$ : For all criteria related to distance from a building to a certain place, a common SD function was constructed $\left(f_{6}\right)$, taking into account the geographical position of the buildings. According to the experts, the following has been considered:

i) For absolute differences until 1,000 meters between the performance of building $a$ and a reference one $b$, and considered that as a short walking distance, therefore "insignificant", there is total similarity $\left(f_{6}\left(\Delta_{6}(a, b)\right)=1\right)$;

ii) A situation of neutrality in terms of similarity-dissimilarity was considered for absolute differences on the range between 2,500 until 3,000 meters $\left(f_{6}\left(\Delta_{6}(a, b)\right)=0\right)$;

iii) Total dissimilarity is assigned to absolute differences greater than 5,000 meters $\left(f_{6}\left(\Delta_{6}(a, b)\right)=\right.$ $-1)$.

Linear interpolation was considered as an adequate way of modeling the values for the remaining possible differences between performances of $a$ and $b$ on criterion $f_{6}$, as represented in Figure 6;

\subsubsection{Assignment of the criteria weights and interaction coefficients}

A well-known procedure for determining criteria weights, the revised Simos' procedure ("SRF method"), was adopted [17] during a focus group with experts in architecture, urban planning (with a specific expertise in accommodating migrants), and project evaluation (other methods for fixing weights in MCDA procedure applied to territorial and urban planning problems have been proposed, such as AHP [28] in [19]; in case of a great number of criteria, to reduce the cognitive burden related to the great number of pairwise comparisons requested, one can apply 


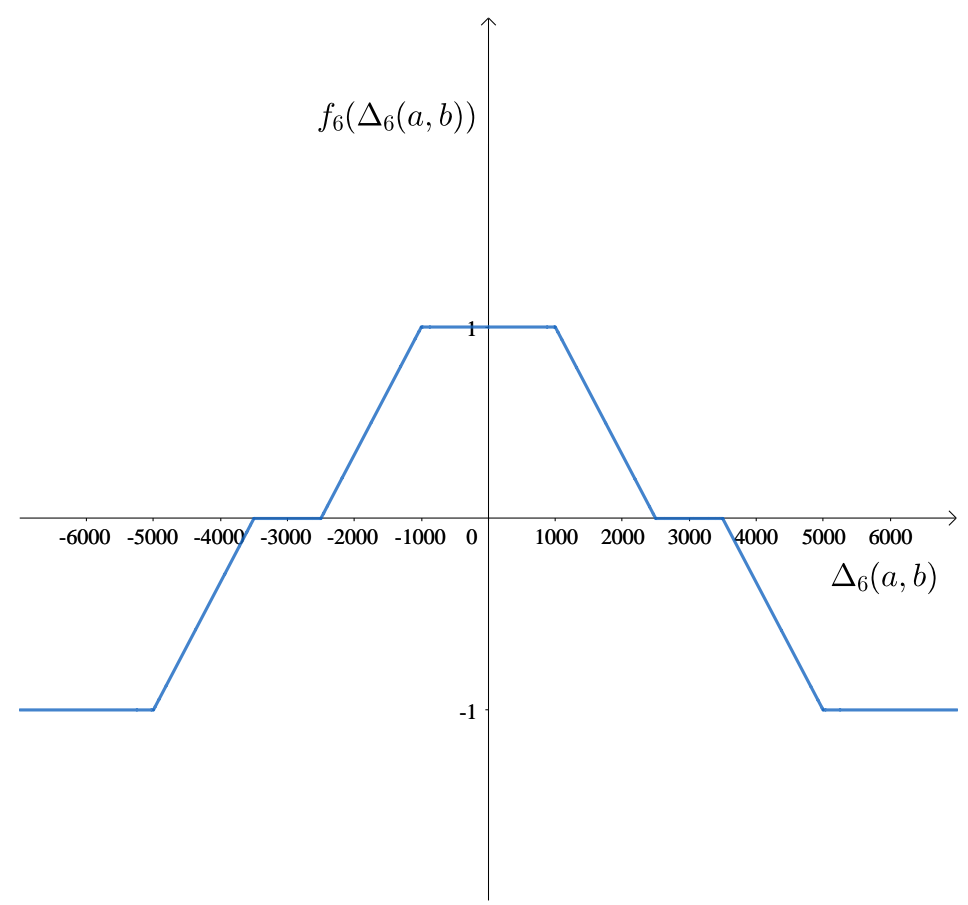

Fig. 6 Representation of the SD function $f_{6}$

the parsimonious AHP proposed in [2]). In general, the SRF method is quite easy to use. In order to assign numerical values to the criteria weights, the method makes use of cards. In this case, twelve cards with the designation of the considered criteria ("criteria cards") and an enough number of blank cards was given to the experts. This set of cards was handled by the experts in the following way, while having in mind one of the three categories:

1. The "criteria cards" were placed from the least important criterion to the most important one to obtain a ranking (criteria judged equally important were placed at the same level), in accordance to the point of view of the experts;

2. Blank cards were placed between two consecutive levels of "criteria cards" assuming that the greater the difference between two consecutive positions, the greater the number of blank cards.

After this procedure of handling cards, we asked the experts how many times the most important criterion (or criteria, if a set of cards is placed at the same level) is more important than the least important one(s). According to the answer, the value was assigned to the ratio $z$, necessary to compute the criteria weights, according to the SRF method.

The described procedure was followed for the remaining two categories. We used the method "SRF" available in DecSpace ${ }^{1}[3,6]$, which has been developed to support multiple criteria decision problems. DecSpace is a web-based platform, which is inspired by diviz [22], having MCDA methods available for any user. In its current version, DecSpace has locally implemented the methods "SRF" and "CAT-SD" . The position of the cards for the three categories is depicted in Figures 7-9 (in all cases, the experts assigned the value 5 to ratio $z$ ).

We highlight some comments given by the experts:

1 Available at http://decspace.sysresearch.org/index.html 


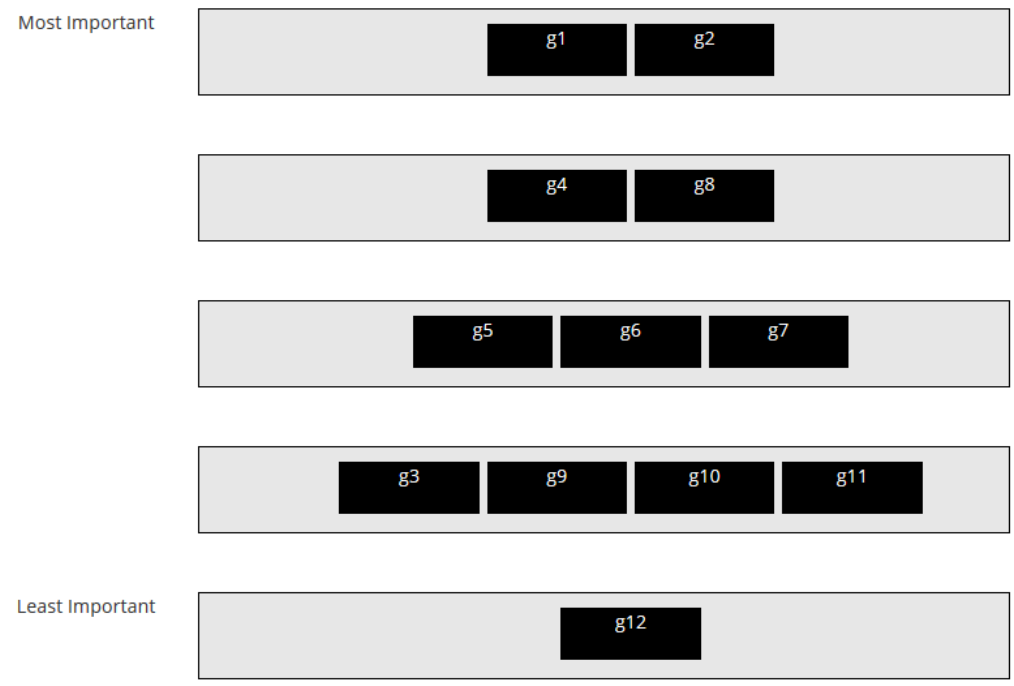

Fig. 7 Ranking of the cards for category $C_{1}$ in DecSpace

- Facing the problem of housing assignment, for all the categories the highest importance has been given to a correspondence to a building typology (differentiated per category) and approximately with the same importance, to the level of degradation of the asset. The latter is related to the fact that the considered buildings require different type of renovations, having an original different function (for instance, industrial buildings could need a reclamation) and having been recently abandoned. The level of degradation corresponds to a higher or lower need of funds for the recovery of the building, and to a different duration of the construction works;

- The asylum seeker is an individual immigrant at the time of her/his arrival in the city, requiring international protection. This status can last from two to twelve months. She/he cannot travel and cannot apply for family reunification, hence requiring a very high level of assistance. She/he needs above all to be guided in the bureaucratic aspects of the system (criterion $g_{8}$ ). The permanence in this status is considered strongly transitory and to avoid excessive isolation of the subject in the first phase of integration in the city network, a space is proposed that favors the collective dimension (criterion $g_{1}$ );

- The refugee is a person who has her/his claim for asylum accepted by the government, meaning that she/he must take the first steps to become part of society. In this sense, the proximity with the prefecture is important, because it manages the system of reception facilities; with the bureaucratic support because the Italian system is rather complex and not immediately understood by a foreigner; with public transportation to carry out the most varied activities (work, educational, recreational) or even simply to know the city where she/he found asylum;

- The family reunification member is considered part of a group of people, and the needs of a family unit are different from the asylum seeker and the refugee. At the spatial level, it is of 


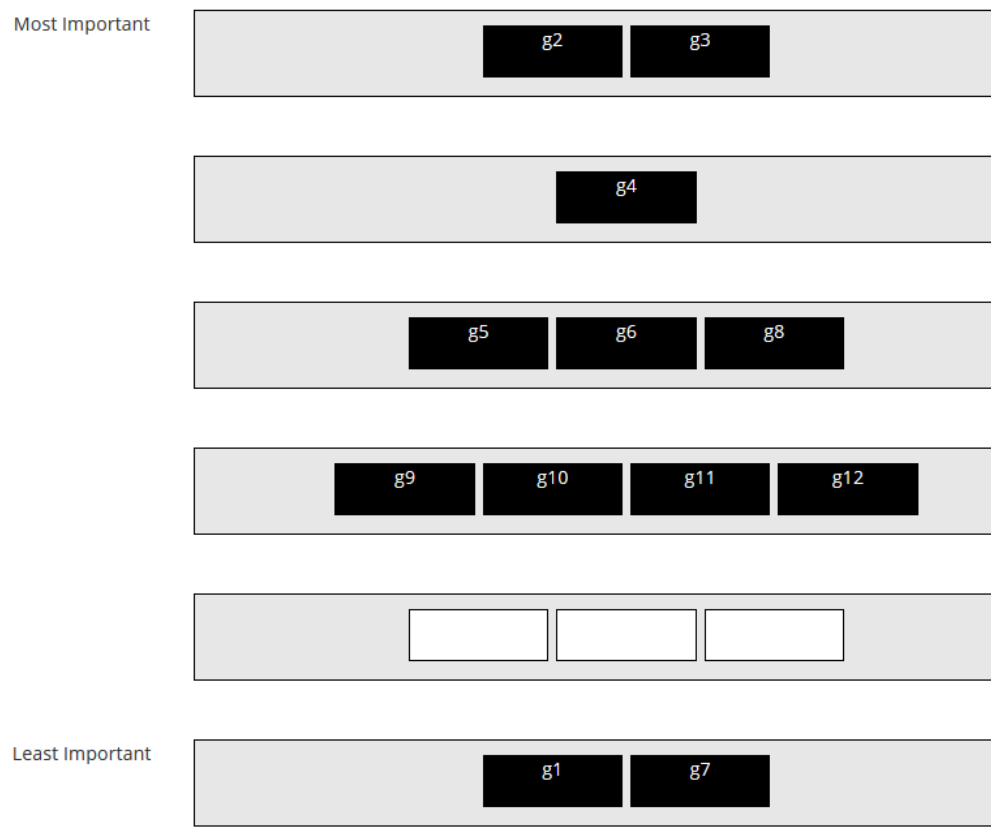

Fig. 8 Ranking of the cards for category $C_{2}$ in DecSpace

primary importance to be able to establish themselves permanently in the urban fabric, with the possibility of living in a flat (criterion $g_{3}$ ), maintaining the guarantee of assistance for training, insertion into the work environment and the possibility of transportation to easily move in the city (criterion $g_{5}$ ).

In that way, we have obtained the criteria weights (non-normalized values) and have shown them to the experts in order to validate these values. After the revision and some discussion, they have judged that, for category $C_{3}$, the values assigned to criteria $g_{2}$ and $g_{7}$ were very high (4.5 and 3.5, respectively). In fact, the presence of typology $\mathrm{C}$ has the highest importance for a family reunification member. Besides typology B has a high relative importance, it was considered that the difference on the weights of $g_{3}(5)$ and $g_{2}$ (4.5) must be higher than 0.5. Revising the values, the experts have considered that the weights of the distance from the prefecture $\left(g_{6}\right)$ and from the police headquarters $\left(g_{7}\right)$ should not be the same, being $g_{7}$ less important than initially considered. Thus, the experts agreed on replacing the criteria weights $k_{2}^{3}$ and $k_{7}^{3}$ by the value 2 instead. The remaining values were considered adequate to represent the relative importance of criteria according to the experts' opinion. The final values of the sets of weights are displayed in Table 5 .

Afterwards, we asked to the experts for possible interactions in pairs of criteria on each of the three categories used to represent a migrant status (see Section 2). Firstly, we explained the three types of interactions that can be modeled [13]. Secondly, we asked them to analyze possible pairs of criteria that could interact and in which type of interaction, considering each category separately. Finally, numerical values were assigned to the interaction effects identified by the experts. The only type of interaction considered in this study was the mutual-strengthening effect (synergy) between two criteria, meaning that, when both criteria contribute to the similarity, 


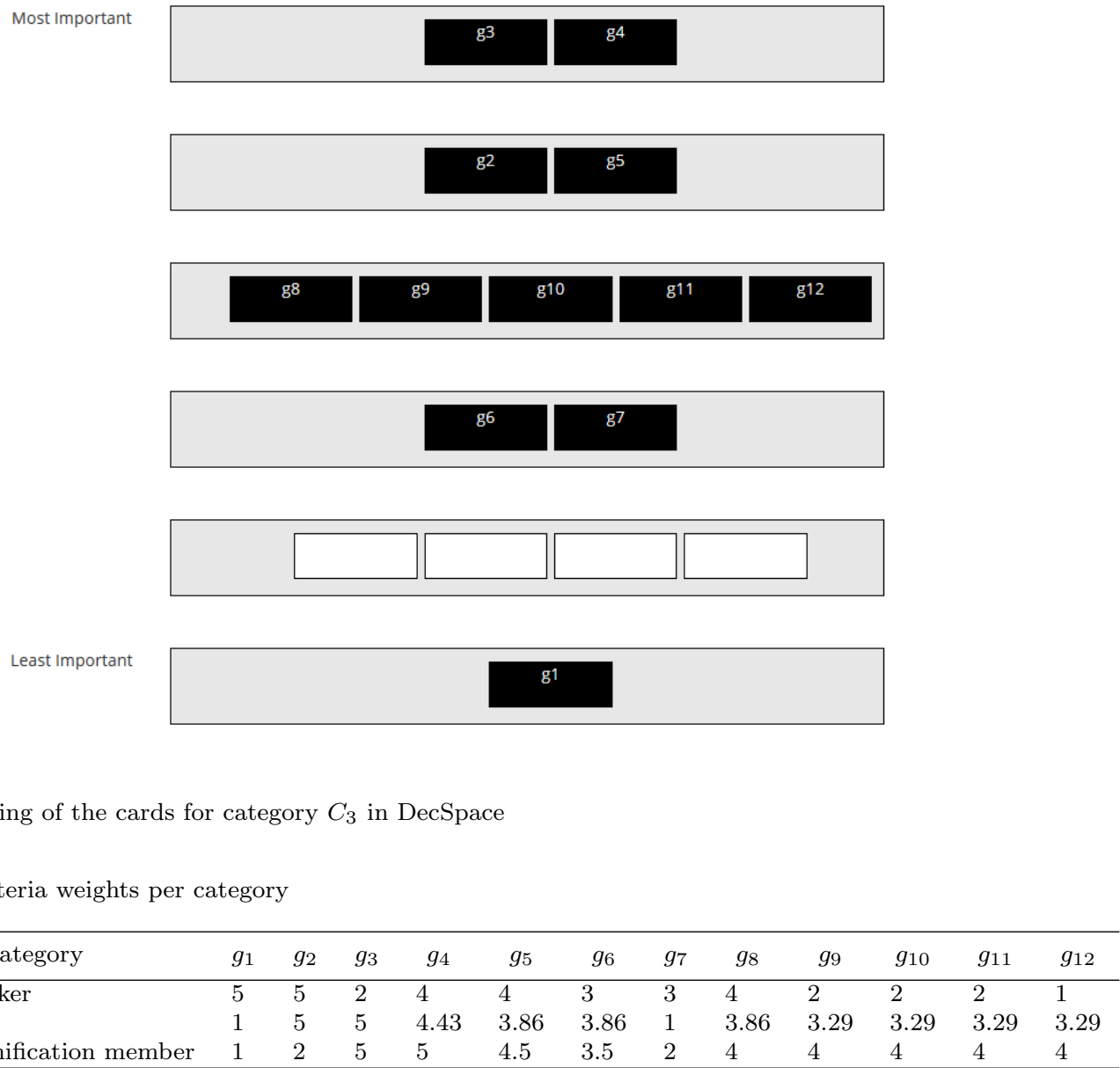

Fig. 9 Ranking of the cards for category $C_{3}$ in DecSpace

Table 5 Criteria weights per category

\begin{tabular}{|c|c|c|c|c|c|c|c|c|c|c|c|c|}
\hline Category & $g_{1}$ & $g_{2}$ & $g_{3}$ & $g_{4}$ & $g_{5}$ & $g_{6}$ & $g_{7}$ & $g_{8}$ & $g_{9}$ & $g_{10}$ & $g_{11}$ & $g_{12}$ \\
\hline Asylum seeker & 5 & 5 & 2 & 4 & 4 & 3 & 3 & 4 & 2 & 2 & 2 & 1 \\
\hline Refugee & 1 & 5 & 5 & 4.43 & 3.86 & 3.86 & 1 & 3.86 & 3.29 & 3.29 & 3.29 & 3.29 \\
\hline Family reunification member & 1 & 2 & 5 & 5 & 4.5 & 3.5 & 2 & 4 & 4 & 4 & 4 & 4 \\
\hline
\end{tabular}

the overall weight of these two criteria is greater than the sum of the weight of the two criteria considered separately. In particular, from the interaction with the experts, the following came out:

- For category $C_{1}$ (asylum seeker), having a building with typology A and a short distance to the police headquarters, as the performance of the reference actions $b_{11}$ and $b_{12}$, is very well appreciated. Therefore, it is necessary to consider a strengthening effect between criteria $g_{1}$ (typology A) and $g_{7}$ (distance from police headquarters) when both conjointly contribute to the overall similarity between a building to be assigned and a building defined as reference. Taking into account the sum of the weights of this pair of criteria, $k_{1}^{1}+k_{7}^{1}=5+3=8$, the experts easily assigned a weight of 10 to the coalition of $g_{1}$ and $g_{7}$. Consequently, $k_{17}^{1}=$ $10-8=2$, that is, the value of this strengthening coefficient is 2 ;

- For category $C_{2}$ (refugee), having a building with typology B and education services nearby, that is, a distance considered similar to $b_{21}$, is fundamental. Therefore, it is necessary to consider a strengthening effect between criteria $g_{2}$ (typology B) and $g_{10}$ (distance from education service) when both conjointly contribute to the overall similarity between a building and a reference one. The sum of the weights of these two criteria is $k_{2}^{2}+k_{10}^{2}=5+3.29=8.29$, 
and the experts assigned a weight of 10.29 to the coalition of the two criteria. Consequently, $k_{2,10}^{2}=10.29-8.29=2$, that is, the value of this strengthening coefficient is 2 ;

- For category $C_{3}$ (family reunification member), having a building with typology $\mathrm{C}$ and a great network of transportation is worth being very well appreciated. It is necessary to consider a strengthening effect between criteria $g_{3}$ (typology C) and $g_{5}$ (public transportation) when both conjointly contribute to the overall similarity between a building and a reference one. For this pair of criteria, the sum of the weights is $k_{3}^{3}+k_{5}^{3}=5+4.5=9.5$, and the weight of the coalition is 11.5 . Consequently, $k_{35}^{3}=11.5-9.5=2$, that is, the value of this strengthening coefficient is 2 .

Table 6 summarizes the information about the interaction effects between criteria, providing, for each category, the criteria pair, the value of the interaction coefficient and a short explanation of the presence of the strengthening effect.

Table 6 Mutual-strengthening effects between criteria

\begin{tabular}{lccl}
\hline \multicolumn{1}{c}{ Category } & Pair & Value & \multicolumn{1}{c}{ Justification } \\
\hline Asylum seeker & $\left\{g_{1}, g_{7}\right\}$ & 2 & $\begin{array}{l}\text { Asylum seekers, at the first phase of arrival, need to be close to the } \\
\text { police headquarters for the bureaucratic procedure and the most } \\
\text { suitable building to host them corresponds to typology A }\end{array}$ \\
\hline Refugee & $\left\{g_{2}, g_{10}\right\}$ & 2 & $\begin{array}{l}\text { After gaining the refugee status, it is fundamental for refugees to learn } \\
\text { the local language and have elements about the culture of the hosting } \\
\text { Country (needs to be close to educational service), at the same time, } \\
\text { the most suitable building to host them corresponds to typology B }\end{array}$ \\
\hline Family reunification member & $\left\{g_{3}, g_{5}\right\}$ & 2 & $\begin{array}{l}\text { It is important to locate a member of family reunification close to public } \\
\text { transports to guarantee that all family members can easily move without } \\
\text { a car, in order to reach the workplace, the schools, meeting places, and } \\
\text { the most suitable building to host them corresponds to typology C }\end{array}$ \\
& & &
\end{tabular}

\subsubsection{Definition of the likeness thresholds per category}

Regarding the likeness thresholds, which are also parameters necessary for the application of the CAT-SD method (see Section 2 and step 3 in Figure 1), the following values were established by the experts: 0.6 for "asylum seeker" $\left(C_{1}\right)$ and "family reunification member" $\left(C_{3}\right)$, and 0.55 for "refugee" $\left(C_{2}\right)$ (i.e., $\lambda^{1}=\lambda^{3}=0.6$ and $\left.\lambda^{2}=0.55\right)$. The small difference between the value chosen for $C_{2}$ and the other two remaining categories has been justified with the argument of a slight demand of overall likeness when assigning a building to a refugee, whom, in general, is relatively adaptable to the accommodation.

\section{Results and discussion}

\subsection{Assignment results}

According to the constructed decision model, described in Section 3 (data and preference parameters), we are able to obtain the classification of the twenty-two buildings into one or more categories, among the four possible nominal categories, which corresponds to step 4 in Figure 1. The assignments provided by the application of the CAT-SD method were obtained by using the DecSpace platform. Figure 10 shows the assignment results.

Consistent with the characteristics of the category, the "asylum seeker" status has presented the greater number of attributions, being the status that requests less in terms of privacy from 


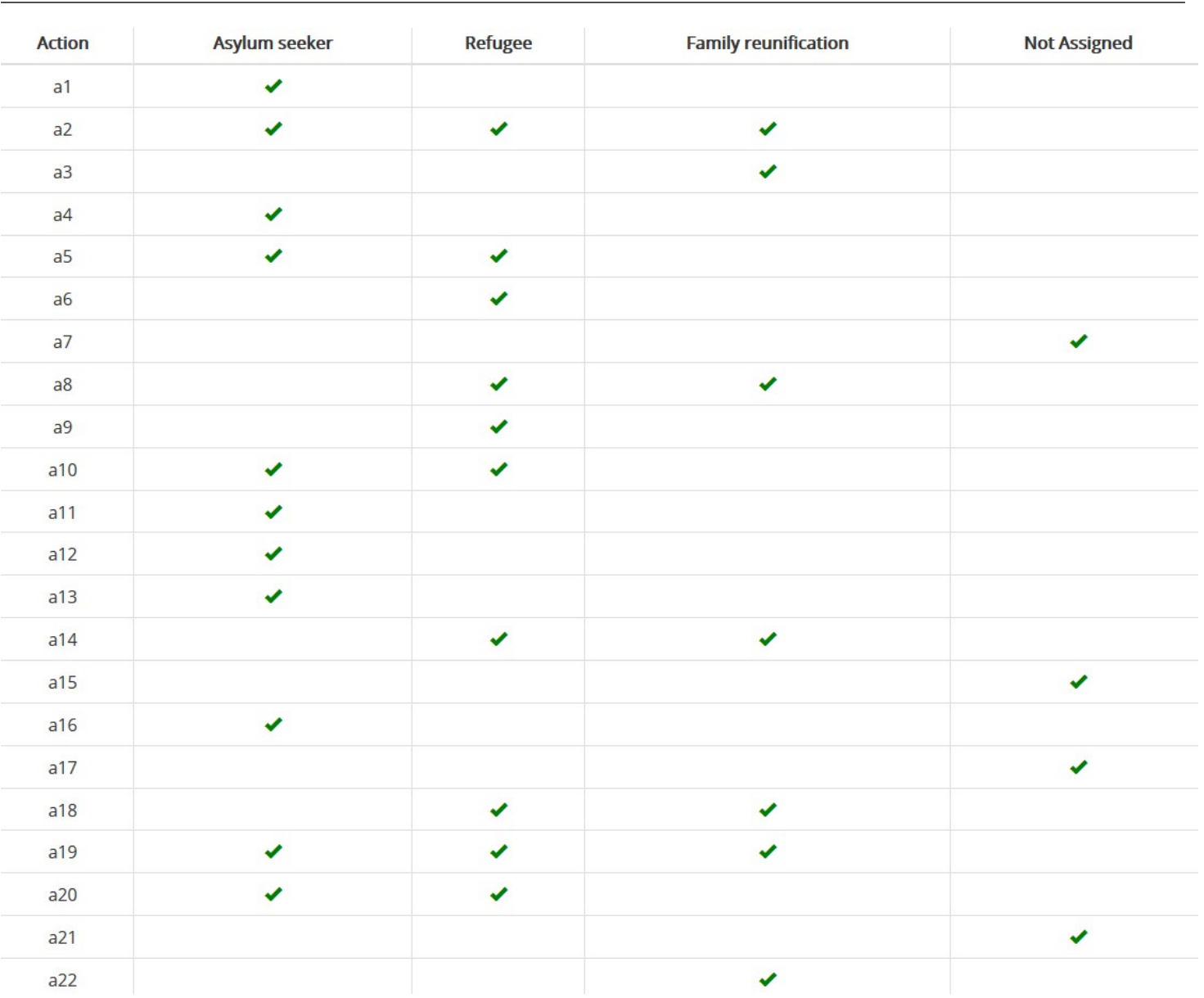

Fig. 10 Assignment of the buildings (from DecSpace)

the residential service and, due to the location of the buildings, all quite well located in the urban fabric. More precisely, eleven buildings have been evaluated as suitable for hosting asylum seekers, seven out of them are former factories. For "refugee" status also several buildings were assessed as adequate for receiving refugees. Due to the demanding requirements for a family reunification member and the current sample, only seven buildings were classified into the category representing such a migrant status. Four buildings proved not to be suitable for hosting any type of migrants: two of them (one ex factory and one ex hospital) probably mainly owing to very poor conditions; and for the other two the distance from the services played an important role in this result.

This analysis significantly contributes to understand the characteristics of the buildings from different points of view and to assess the suitability of buildings in their current status to accommodate people with different migrant status. The experts have considered that the results achieved are a relevant output for the next step of the decision process related to the Refugee Accommodation System in Turin, that is, the buildings rehabilitation to adequately host new inhabitants. Some interventions may take place in the near future, in order to better adapt the buildings to people arriving. However, the idea is to minimize interventions and quickly prepare the buildings for the accommodation of migrants. 


\subsection{Robustness analysis}

A decision model has been built and the results of the application of the CAT-SD method were considered satisfactory. However, a set of weights obtained by the application of the revised Simos' procedure were not immediately considered adequate by the experts (the obtained values were revised and consensually redefined, as described in Section 3). Moreover, towards a discussion about the difficulties concerning the assignment of the values to the preference parameters, we got from the experts that a certain difficulty were felt in choosing the values of the likeness thresholds. They referred that this was not straightforward and that closed values would possibly be also acceptable. Even though we have expected that could be difficult to understand and define the remaining parameters (e.g., per-criterion functions and interaction coefficients), they were easily understood by the experts after our explanations. Thus, we proposed to conduct a robustness analysis to assess how changes in parameters would affect the actions' assignments.

A robustness analysis has been done by analyzing a set of scenarios created through the change of the values of the criteria weights and the likeness thresholds defined for each category. In order to obtain new sets of weights, we modified the number of blank cards in between consecutive criteria positions in the constructed rankings (see Figures 7-9). Considering each category individually, we proceed as follows:

- For category $C_{1}$, we produced four experiments related to the corresponding weight set obtained by:

1. Adding a single blank card between the first and the second ranked groups of criteria;

2. Adding a single blank card between the second and the third ranked groups of criteria;

3. Adding a single blank card between the third and the fourth ranked groups of criteria;

4. Adding a single blank card between the fourth and the fifth ranked groups of criteria;

- For category $C_{2}$, we produced five experiments related to the corresponding weight set obtained by:

1. Adding a blank card in each interval between groups of criteria;

2. Adding a single blank card between the first and the second ranked groups of criteria;

3. Adding a single blank card between the second and the third ranked groups of criteria;

4. Adding a single blank card between the third and the fourth ranked groups of criteria;

5. Adding a single blank card between the fourth and the fifth ranked groups of criteria (in this case the number of cards between the two groups passed from 3 to 4);

- For category $C_{3}$ we performed six experiments:

1. Adding a blank card in each interval between groups of criteria;

2. Adding a single blank card between the first and the second ranked groups of criteria;

3. Adding a single blank card between the second and the third ranked groups of criteria;

4. Adding a single blank card between the third and the fourth ranked groups of criteria;

5. Adding a single blank card between the fourth and the fifth ranked groups of criteria (in this case the number of cards between the two groups passed from 4 to 5);

6. Considering the non-corrected weight set, the one initially obtained with the deck of cards procedure (see Figure 9).

It should be refereed that we did not perform the experiment of adding a blank card between consecutive criteria' groups for the case of $C_{1}$, since the weight set obtained corresponds to the set considered in the model, i.e., $k^{1,1}$. In experiments $1-5$ of category $C_{3}$, we proportionally reduced the values assigned to the weights of $g_{2}$ and $g_{7}$ in accordance with the judgments of the DM previously described. Table 7 displays all sets of weights obtained in accordance with the experiments described above, as well as the ones previously used in the model.

Besides the additional sets of weights, distinct values for the likeness thresholds were taken into account in this analysis. This was done by an increase and a decrease in 0.05 of the initial 
Table 7 Sets of weights considered in the robustness analysis

\begin{tabular}{|c|c|c|c|c|c|c|c|c|c|c|c|c|c|}
\hline Category & Weight set & $k_{1}^{h}$ & $k_{2}^{h}$ & $k_{3}^{h}$ & $k_{4}^{h}$ & $k_{5}^{h}$ & $k_{6}^{h}$ & $k_{7}^{h}$ & $k_{8}^{h}$ & $k_{9}^{h}$ & $k_{10}^{h}$ & $k_{11}^{h}$ & $k_{12}^{h}$ \\
\hline \multirow[t]{5}{*}{$C_{1}$} & $k^{1,1}$ & 5 & 5 & 2 & 4 & 4 & 3 & 3 & 4 & 2 & 2 & 2 & 1 \\
\hline & $k^{1,2}$ & 5 & 5 & 1.8 & 3.4 & 2.6 & 2.6 & 2.6 & 3.4 & 1.8 & 1.8 & 1.8 & 1 \\
\hline & $k^{1,3}$ & 5 & 5 & 1.8 & 4.2 & 2.6 & 2.6 & 2.6 & 4.2 & 1.8 & 1.8 & 1.8 & 1 \\
\hline & $k^{1,4}$ & 5 & 5 & 1.8 & 4.2 & 3.4 & 3.4 & 3.4 & 4.2 & 1.8 & 1.8 & 1.8 & 1 \\
\hline & $k^{1,5}$ & 5 & 5 & 2.6 & 4.2 & 3.4 & 3.4 & 3.4 & 4.2 & 2.6 & 2.6 & 2.6 & 1 \\
\hline \multirow[t]{6}{*}{$C_{2}$} & $k^{1,2}$ & 1 & 5 & 5 & 4.43 & 3.86 & 3.86 & 1 & 3.86 & 3.29 & 3.29 & 3.29 & 3.29 \\
\hline & $k^{2,2}$ & 1 & 5 & 5 & 4.27 & 3.35 & 3.35 & 1 & 3.35 & 2.82 & 2.82 & 2.82 & 2.82 \\
\hline & $k^{2,3}$ & 1 & 5 & 5 & 4 & 3.5 & 3.5 & 1 & 3.5 & 3 & 3 & 3 & 3 \\
\hline & $k^{2,4}$ & 1 & 5 & 5 & 4.5 & 3.5 & 3.5 & 1 & 3.5 & 3 & 3 & 3 & 3 \\
\hline & $k^{2,5}$ & 1 & 5 & 5 & 4.5 & 4 & 4 & 1 & 4 & 3 & 3 & 3 & 3 \\
\hline & $k^{2,6}$ & 1 & 5 & 5 & 4.5 & 4 & 4 & 1 & 4 & 3.5 & 3.5 & 3.5 & 3.5 \\
\hline \multirow[t]{7}{*}{$C_{3}$} & $k^{3,1}$ & 1 & 2 & 5 & 5 & 4.5 & 3.5 & 2 & 4 & 4 & 4 & 4 & 4 \\
\hline & $k^{3,2}$ & 1 & 1.92 & 5 & 5 & 4.33 & 3 & 1.71 & 3.67 & 3.67 & 3.67 & 3.67 & 3.67 \\
\hline & $k^{3,3}$ & 1 & 1.83 & 5 & 5 & 4.11 & 3.22 & 1.84 & 3.67 & 3.67 & 3.67 & 3.67 & 3.67 \\
\hline & $k^{3,4}$ & 1 & 2.03 & 5 & 5 & 4.56 & 3.22 & 1.84 & 3.67 & 3.67 & 3.67 & 3.67 & 3.67 \\
\hline & $k^{3,5}$ & 1 & 2.03 & 5 & 5 & 4.56 & 3.22 & 3.22 & 4.11 & 4.11 & 4.11 & 4.11 & 4.11 \\
\hline & $k^{3,6}$ & 1 & 2.03 & 5 & 5 & 4.56 & 3.67 & 2.1 & 4.11 & 4.11 & 4.11 & 4.11 & 4.11 \\
\hline & $k^{3,7}$ & 1 & 4.5 & 5 & 5 & 4.5 & 3.5 & 3.5 & 4 & 4 & 4 & 4 & 4 \\
\hline
\end{tabular}

considered values. Accordingly, the following values were considered (including the predefined values):

$-C_{1}: \lambda^{1,1}=0.6, \lambda^{1,2}=0.55$ and $\lambda^{1,3}=0.65$

$-C_{2}: \lambda^{2,1}=0.55, \lambda^{2,2}=0.50$ and $\lambda^{2,3}=0.60$

$-C_{3}: \lambda^{3,1}=0.6, \lambda^{3,2}=0.55$ and $\lambda^{3,3}=0.65$.

Thus, for each category, three values of likeness thresholds were combined with the sets of weights, including the sets previously defined in the constructed model. Note that the assignment of an action to a given category is independent from the assignment to another category. For this reason, for each category, we performed an analysis of different scenarios, which were constructed by combining the distinct weight sets and the values of the likeness thresholds. This corresponds to a total number of scenarios of 15 for $C_{1}, 18$ for $C_{2}$ and 21 for $C_{3}$.

The results of this analysis are presented in Table 8 . Each column, corresponding to a category, presents the percentage of scenarios (rounded to unit) in which each building is assigned to such a category. As one can verify by analyzing this table, most of the buildings' assignments are unchanged in the considered scenarios. We can conclude that thirteen out of twenty-two buildings has a stable classification: buildings $a_{1}, a_{2}, a_{4}, a_{8}, a_{12}, a_{13}, a_{14}, a_{19}$ and $a_{22}$ maintain the assignment to at least one category of migrant status; and buildings $a_{7}, a_{15}, a_{17}$, and $a_{21}$ are never assigned to a category of this kind, that is, they are assigned to category $C_{4}$ in all scenarios. In particular, we have verified that buildings $a_{11}$ and $a_{20}$ are not assigned to $C_{1}$ with $\lambda^{1,3}$ (i.e., 0.65), $a_{16}$ is assigned to $C_{2}$ with $\lambda^{2,2}$ (i.e., 0.50), and $a_{9}$ and $a_{18}$ are not assigned to $C_{2}$ with $\lambda^{2,3}$ (i.e., 0.60), $a_{5}$ is assigned to $C_{3}$ with $\lambda^{3,2}$ (i.e., 0.55), while using any respective weight set. Thus, in this case study, it can be considered that stable assignment results have been obtained when the CAT-SD method is applied.

\section{Social implications}

The migration phenomenon is no longer an emergency, it is instead structural and growing. Despite this, migrants represent the great dilemma of Europe. The European Union has reacted 
Table 8 Percentage of scenarios with assignment of the building to each category

\begin{tabular}{lrrr}
\hline Building & $C_{1}$ & $C_{2}$ & $C_{3}$ \\
\hline$a_{1}$ & 100 & 0 & 0 \\
$a_{2}$ & 100 & 100 & 100 \\
$a_{3}$ & 0 & 0 & 67 \\
$a_{4}$ & 100 & 0 & 0 \\
$a_{5}$ & 100 & 100 & 33 \\
$a_{6}$ & 0 & 100 & 24 \\
$a_{7}$ & 0 & 0 & 0 \\
$a_{8}$ & 0 & 100 & 100 \\
$a_{9}$ & 0 & 67 & 0 \\
$a_{10}$ & 100 & 100 & 5 \\
$a_{11}$ & 67 & 0 & 0 \\
$a_{12}$ & 100 & 0 & 0 \\
$a_{13}$ & 100 & 0 & 0 \\
$a_{14}$ & 0 & 100 & 100 \\
$a_{15}$ & 0 & 0 & 0 \\
$a_{16}$ & 100 & 33 & 0 \\
$a_{17}$ & 0 & 0 & 0 \\
$a_{18}$ & 0 & 67 & 90 \\
$a_{19}$ & 100 & 100 & 100 \\
$a_{20}$ & 67 & 100 & 0 \\
$a_{21}$ & 0 & 0 & 0 \\
$a_{22}$ & 0 & 0 & 100 \\
\hline & & &
\end{tabular}

to the migration crisis without an overall strategy, adopting a series of emergency procedures. The phenomenon has tested the cohesion of the European countries that have acted by adopting specific, often contradictory policies. While waiting to have a coherent European framework for managing the reception of migrants, individual countries must still cope with the phenomenon.

This case study is aligned with the policy agendas, contributing for defining actions aimed at an effective coordination between public, private and third sector activities, for designing well-managed housing migration policies. Before providing the city of inclusive equipment from the architect point of view, firstly decisions have to be made based on the existing network and a decision aiding process has to be followed to clearly establish the goals to be achieved. Thus, the main aim is to define a strategy to include in the local context of hospitality centers, without orienting the immigrants in random structures, but planning their placement in urban space, followed by a process of regeneration, recovery and revitalization of discontinuous areas in the Turin territory, with other uses for the underused buildings. This study enhances that the execution of an urban strategy is essential for the inclusion of migrants in the urban context.

To sum up, this study contributes to define a direction for adaptive reuse of existing vacant buildings and abandoned sites for housing and integrating forced migrants in a local urban context. Undoubtedly, housing is one of the most important aspects related to the integration of migrants. Indeed, reusing those buildings can provide adequate accommodation and accessibility to public services, and consequently it can offer an opportunity of social integration for refugees. In this sense, revitalization of such buildings and sites by housing new inhabitants may raise socio-spatial sustainability. This is a starting point to define housing policies to effectively support displaced people.

\section{Conclusions}

The paper proposes a tool that could improve the decision aiding process in the Refugee Accommodation System in Turin, which can be applied to any other similar problems. The idea 
underlying the proposal is that both, the cities and the "collective" of refugees, could benefit from an urban strategy that connects people, services and regenerates urban areas in decline.

The application of the CAT-SD method contributed to the nominal classification problem at hand by assigning each underused building to the non-ordered categories, considering the experts' judgments. More specifically, through a constructive approach, twenty-two underused buildings in the city of Turin were identified, and three nominal categories were considered. Each category represents a specific status of people in need of protection and assistance as a consequence of forced displacement, to be hosted in the underused buildings. Reference buildings were defined per category with the purpose of comparing each building to them, taking into consideration the preferences of the experts. Then, a set of spatial and geographical characteristics were considered to construct a set of criteria. Thereafter, by applying the CAT-SD method, the buildings were assigned to adequate categories, while all criteria were taken into account.

According to the results of robustness analysis we carried out, it was proven that assignments obtained through CAT-SD were stable. This allowed us to formulate robust conclusions with respect to the assignment of the buildings to the considered categories.

It is worth highlighting the challenge represented by the idea to "model" a complicated theme such as the immigration phenomenon. This required a strong simplification: having reduced the criteria to a "choice of position" and distance from the services offered by the existing network in Turin.

As a recommendation for further research, we propose the following: about the method, an interesting direction of research could be the systematic consideration of robustness concerns, through a well articulated robustness analysis of the constructed MCDA model. About the realm of the application, it would be interesting to include also social and political criteria. With this aim, Multiple Criteria Hierarchy Process (MCHP) [11] can be applied to logically group subsets of criteria (e.g., technical, social and political) in a hierarchy, as proposed in [12]. Thus, other aspects can also be considered as criteria and adequately handled with the MCHP, offering a broader analysis of the decision situation regarding the housing assignment.

Given the refugee crisis faced by many European countries, the proposed MCDA analysis has doubly a relevant potential of being applied to other European cities. Thus, the constructed model may be applied to similar decision contexts of other cities, aiming at identifying the most adequate buildings placed in the city without current use but with potential to host people in displaced conditions. As have been shown in this study, the application of the CAT-SD method allows to integrate different perspectives and interests of the various stakeholders involved in the decision problem. Accordingly, as a future perspective of study, it could be interesting to apply the constructed decision model to similar scenarios in other cities, namely in Europe.

As for the next step involving the re-qualification of the underused buildings considered in this study, the cost of the intervention in each building must be considered. We can formulate a portfolio decision problem in which from a set of re-qualification projects (portfolio), a subset is selected, while some constraints are considered, as in [5]. An alternative approach can be adopted as in [4]. In such a scenario, there is a cost associated with each project and limited resources, namely the available budget. In could be also relevant to consider risk and uncertainty associated with each project. More in general, the approach we are proposing can be applied to any decision related to territorial and urban planning. Thus, stakeholders and experts can be supported to define destination of areas and buildings of interest through an adequate multiple criteria decision aiding based nominal classification procedure. 


\section{Acknowledgments}

The authors acknowledge the anonymous referees for their valuable comments, remarks, and suggestions on a previous version of this paper. Ana Sara Costa acknowledges financial support from Universidade de Lisboa, Instituto Superior Técnico, and CEG-IST (PhD Scholarship). Ana Sara Costa and José Borbinha were supported by national funds through Fundação para a Ciência e a Tecnologia (FCT) with reference UID/CEC/50021/2019. Salvatore Greco wishes to acknowledge the funding by the FIR of the University of Catania "BCAEA3, New developments in Multiple Criteria Decision Aiding (MCDA) and their application to territorial competitivenes" and by the research project "Data analytics for entrepreneurial ecosystems, sustainable development and wellbeing indices" of the Department of Economics and Business of the University of Catania. Salvatore Greco has also benefited of the fund "Chance" of the University of Catania. José Rui Figueira acknowledges the support from the FCT grant SFRH/BSAB/139892/2018. The authors wish to thank Prof. Alessandro Armando (Politecnico di Torino) for providing the opportunity for the experimentation presented in the study. A special thank goes also to Martina Bunino, Silvia Bovo and Zeynep Tulumen for the data used in the research and for developing some preliminary part of the study.

\section{References}

1. Abastante, F., Corrente, S., Greco, S., Ishizaka, A., Lami, I.M.: Choice architecture for architecture choices: Evaluating social housing initiatives putting together a parsimonious AHP methodology and the Choquet integral. Land Use Policy 78, 748-762 (2018)

2. Abastante, F., Corrente, S., Greco, S., Ishizaka, A., Lami, I.M.: A new parsimonious AHP methodology: Assigning priorities to many objects by comparing pairwise few reference objects. Expert Systems with Applications 127, 109-120 (2019)

3. Amador, J., Costa, A.S., Rodrigues, R., Figueira, J.R., Borbinha, J.: Exploring MCDA methods with DECSpace. In: P. Silva, R. Quaresma, T. Oliveira (eds.) 18th Conference of the Portuguese Association for Information Systems - Industry 4.0 and Information Systems. Associação Portuguesa de Sistemas de Informação, Santarém, Portugal (2018)

4. Barbati, M., Figueira, J.R., Greco, S., Ishizaka, A., Panaro, S.: A multiple criteria methodology for prioritizing and selecting portfolios of urban projects. arXiv:1812.10410 (2018)

5. Barbati, M., Greco, S., Kadziński, M., Słowiński, R.: Optimization of multiple satisfaction levels in portfolio decision analysis. Omega 78, 192-204 (2018)

6. Barbosa, A.: Decspace: A multi-criteria decision analysis framework. Master's thesis, Instituto Superior Técnico, Universidade de Lisboa, Lisboa, Portugal (2017)

7. Belacel, N.: Multicriteria assignment method ProAfTN: Methodology and medical application. European Journal of Operational Research 125(1), 175-183 (2000)

8. Belacel, N., Boulassel, M.R.: Multicriteria fuzzy classification procedure Procftn: Methodology and medical application. Fuzzy Sets and Systems 141(2), 203-217 (2004)

9. Bottero, M., Ferretti, V., Figueira, J.R., Greco, S., Roy, B.: Dealing with a multiple criteria environmental problem with interaction effects between criteria through an extension of the ELECTRE III method. European Journal of Operational Research 245(3), 837-850 (2015)

10. Bunino, M., Bovo, S., Tulumen, Z.: Settle into. strategie inclusive per i nuovi abitanti. Master's thesis, Politecnico di Torino, Turin, Italy (2017). Retrived from http://webthesis.biblio.polito.it/id/eprint/ 6093

11. Corrente, S., Greco, S., Słowiński, R.: Multiple criteria hierarchy process in robust ordinal regression. Decision Support Systems 53(3), 660-674 (2012)

12. Costa, A.S., Corrente, S., Greco, S., Figueira, J.R., Borbinha, J.: A robust hierarchical nominal classification method based on similarity and dissimilarity. arXiv:1812.08596 (2018)

13. Costa, A.S., Figueira, J.R., Borbinha, J.: A multiple criteria nominal classification method based on the concepts of similarity and dissimilarity. European Journal of Operational Research 271(1), 193-209 (2018). Doi: 10.1016/j.ejor.2018.05.029

14. Costa, A.S., Lami, I.M., Greco, S., Figueira, J.R., Borbinha, J.: A multiple criteria approach defining cultural adaptive reuse of abandoned buildings. In: M. Huber S. Geiger, A. de Almeida (eds.) Multiple Criteria Decision Making and Aiding - Cases on Decision Making Methods and Models with Computer Implementations, pp. 193-218. Springer, Cham, Switzerland (2019) 
15. Doumpos, M., Zopounidis, C.: Multicriteria Decision Aid Classification Methods. Kluwer Academic Publishers, Dordrecht, The Netherlands (2002)

16. Figueira, J.R., Greco, S., Roy, B.: Electre methods with interaction between criteria: An extension of the concordance index. European Journal of Operational Research 199(2), 478-495 (2009)

17. Figueira, J.R., Roy, B.: Determining the weights of criteria in the Electre type methods with a revised Simos' procedure. European Journal of Operational Research 139(2), 317-326 (2002)

18. Greco, A., Ehrgott, M., Figueira, J.: Multiple Criteria Decision Analysis: State of the Art Surveys, 2nd edn. Springer Science+Business Media, New York, NY (2016)

19. Lee, G.K., Chan, E.H.: The Analytic Hierarchy Process (AHP) approach for assessment of urban renewal proposals. Social Indicators Research 89(1), 155-168 (2008)

20. Léger, J., Martel, J.M.: A multicriteria assignment procedure for a nominal sorting problematic. European Journal of Operational Research 138(2), 349-364 (2002)

21. MakingHeimat: Making Heimat - Refugee Housing Projects. http://www.makingheimat.de/en/ refugee-housing-projects (2018)

22. Meyer, P., Bigaret, S.: Diviz: A software for modeling, processing and sharing algorithmic workflows in MCDA. Intelligent Decision Technologies 6, 283-296 (2012)

23. Perny, P.: Multicriteria filtering methods based on concordance and non-discordance principles. Annals of Operations Research 80, 137-165 (1998)

24. RefugeeCouncilUK: Refugee Council UK - Asylum Seekers. https://www.refugeecouncil.org.uk/policy_ research/the_truth_about_asylum/the_facts_about_asylum (2018)

25. Roy, B.: Méthodologie Multicritère d'Aide à la Décision. Economica, Paris, France (1985)

26. Roy, B.: Multicriteria Methodology for Decision Aiding. Kluwer Academic Publishers, Dordrecht, The Netherlands (1996)

27. Roy, B., Bouyssou, D.: Aide Multicritère à la Décision: Méthodes et Cas. Economica, Paris, France (1993)

28. Saaty, T.L.: A scaling method for priorities in hierarchical structures. Journal of mathematical psychology 15(3), 234-281 (1977)

29. UNHCR: Convention and Protocol Relating to the Status of Refugees. United Nations High Commissioner for Refugees. (1951). Retrieved from http://www.unhcr.org/3b66c2aa10

30. UNHCR: Global Trends - Forced Displacement in 2017. United Nations High Commissioner for Refugees. (2018). Retrieved from http://www.unhcr.org/5b27be547.pdf

31. UNHCR: UNHCR - Education. http://www.unhcr.org/education.html (2018)

32. Zopounidis, C., Doumpos, M.: Multicriteria classification and sorting methods: A literature review. European Journal of Operational Research 138(2), 229-246 (2002) 